NBER WORKING PAPER SERIES

\title{
THE ROLE OF PERMANENT INCOME AND DEMOGRAPHICS IN BLACK/WHITE DIFFERENCES IN WEALTH
}

\author{
Joseph G. Altonji \\ Ulrich Doraszelski \\ Working Paper 8473 \\ http://www.nber.org/papers/w8473 \\ NATIONAL BUREAU OF ECONOMIC RESEARCH \\ 1050 Massachusetts Avenue \\ Cambridge, MA 02138 \\ September 2001
}

We thank Ken Housinger for assisting us with the data. We also thank Michaela Draganska, Bruce Meyer, and seminar participants at the Federal Reserve Bank of Chicago (May 1999), Northwestern University (December 2000), and the University of Wisconsin (June 2001) for helpful comments. We are grateful for support from the Federal Reserve Bank of Chicago, the Russell Sage Foundation, and the Institute for Policy Research at Northwestern University. We owe a special debt to Lewis Segal who collaborated with us in the early stages of the project. A less technical, abbreviated summary of some of the research reported here may be found in Altonji, Doraszelski \& Segal (2000). All opinions and errors axe our own. The views expressed herein are those of the authors and not necessarily those of the National Bureau of Economic Research.

(C) 2001 by Joseph G. Altonji and Ulrich Doraszelski. All rights reserved. Short sections of text, not to exceed two paragraphs, may be quoted without explicit permission provided that full credit, including $(\subset$ notice, is given to the source. 
The Role of Permanent Income and Demographics in Black/White Differences in Wealth Joseph G. Altonji and Ulrich Doraszelski

NBER Working Paper No. 8473

September 2001

JEL No. D1, D31, D91, E21

\begin{abstract}
$\underline{\text { ABSTRACT }}$
We explore the extent to which the huge race gap in wealth can be explained with properly constructed income and demographic variables. In some instances we explain the entire wealth gap with income and demographics provided that we estimate the wealth model on a sample of whites. However, we typically explain a much smaller fraction when we estimate the wealth model on a black sample. Using sibling comparisons to control for intergenerational transfers and the effects of adverse history, we find that differences in income and demographics are not likely to account for the lower explanatory power of the black wealth models. Our analysis of growth models of wealth suggests that differences in savings behavior and/or rates of return play an important role.
\end{abstract}

Joseph G. Altonji

Department of Economics

Northwestern University

Evanston, IL 60208

and NBER

altonji@northwestern.edu
Ulrich Doraszelski

Hoover Institution

Tower Room 24

Stanford, CA 94305-6010

doraszelski@hoover.stanford.edu 


\section{Introduction}

The wealth gap between whites and blacks in the United States is much larger than the gap in earnings. For example, Menchik \& Jianakoplos (1997) document that the average wealth of black households is $20 \%$ of the average wealth of white households in the 1976 National Longitudinal Survey of mature men and $23 \%$ in the Survey of Consumer Finances, even though average black income is $60 \%$ and $50 \%$ of average white income in the two samples.

The gap in wealth has implications for the social position of African Americans that go far beyond its obvious implications for the consumption levels that households can sustain. This is because wealth is a source of political and social power, influences access to capital for new businesses, and provides insurance against fluctuations in labor market income. It affects the quality of housing, neighborhoods, and schools a family has access to as well as the ability to finance higher education. The fact that friendships and family ties tend to be within racial groups serves to amplify the effect of the race gap in wealth on the financial, social, and political resources available to blacks relative to whites.

What explains the wealth gap? Previous studies by Blau \& Graham (1990), Smith (1995), Avery \& Rendall (1997), and Menchik \& Jianakoplos (1997) find that race differences in the distribution of key income and demographic variables do not account for most of the wealth gap. Blau \& Graham (1990), Avery \& Rendall (1997), and Menchik \& Jianakoplos (1997) all find that there are large differences between whites and blacks in the relationship between income and demographic and wealth, and that income and demographic factors explain more of the wealth gap when Blinder-Oaxaca type regression decompositions are performed using the coefficients of the wealth model for whites. The large unexplained discrepancy in wealth holding has led some researchers, starting with Blau \& Graham (1990), to hypothesize that differences in inter vivos transfers and inheritances play a major part 
in the wealth gap. Indeed, Smith (1995), Avery \& Rendall (1997), and Menchik \& Jianakoplos (1997) suggests that differences in intergenerational transfers contribute to wealth disparities. However, limitations in the way these previous studies have examined the contribution of income and demographic patterns to the wealth gap make conclusions about the importance of these factors and the differences in the white and black wealth models worth revisiting.

First, the existing studies do not use an adequate measure of permanent income, which is a key determinant of wealth. Due to data limitations Smith (1995) and Avery \& Rendall (1997) base their wealth models on current income alone rather than on current and permanent income. Blau \& Graham (1990) and Menchik \& Jianakoplos (1997) decompose income into current income and permanent income, where permanent income is the component that is predictable given race, sex, age, education, health status, number of children, and geographic location. However, much of the variation in permanent income is within the so-defined cells. Were wealth a linear function of income, ignoring the within-cell variation would not be much of an issue. However, wealth is a nonlinear function of income and the use of the within-cell variation is necessary to precisely estimate wealth models. Moreover, because high-income individuals tend to have disproportionately large wealth holdings, failure to accurately measure the tails of the distribution of permanent income might lead to incorrect estimates of the contribution of permanent income to the wealth gap.

Second, previous studies control for current demographic variables such as marital status and presence of children but not demographic histories. Since wealth at a point in time reflects a flow of savings over many previous years, however, it is likely to be influenced by demographic histories as well as by current demographic variables.

We take a closer look at the role of permanent income and demographics in the race gap in wealth holding using panel data on non-asset income 
from the Panel Study of Income Dynamics (PSID) to measure permanent income. ${ }^{1}$ We also construct marriage histories and child bearing and rearing histories. Our aim is to explore to what extent the wealth gap can be explained with income and demographic variables.

Several factors turn this into a nontrivial exercise. First, the skewed distribution of wealth holding along with the significant fractions of observations with negative wealth holding cause problems for standard functional forms, such as the log of wealth and the level of wealth. Second, demographic variables interact with income variables in determining wealth holdings, thus demanding models that accommodate a rich pattern of interactions between the two sets of variables. To address these issues we use both mean and median regression and work with models of the wealth/income ratio as well as the level and log of wealth.

A third problem arises from the substantial differences between the white and black distributions of demographics and income in combination with the fact that relatively flexible functional forms must be used to capture the nonlinearity of wealth in income. These two features make it is difficult to accurately estimate race specific wealth models over the full range of income. ${ }^{2}$ We address this "nonoverlap" problem in two ways. The first and standard approach is to evaluate the difference in wealth at the mean of all variables for the pooled sample of whites and blacks. The second and new approach is to use the estimated standard error of predicted wealth for individuals from one group based on the wealth model for the other group as a guide toward choosing comparison groups of blacks and whites. The idea is that if the estimated standard error for an individual is relatively small, then the individual is more within sample in a multivariate sense.

\footnotetext{
${ }^{1}$ Hurst, Luoh \& Stafford (1998) also use the PSID to examine race differences in both wealth levels and wealth accumulation. They use the average of income over the previous 5 years as their measure of permanent income. We discuss their results below.

${ }^{2}$ Henceforth income is short for non-asset income and all amounts quoted are deflated to 1989 US\$ using the CPIU.
} 
In the case of single men and single women, we can explain the entire race gap in the level of wealth with income and demographics provided that we estimate the wealth equation on the white sample. In contrast, we typically explain only a small fraction when we estimate the wealth model on a sample of blacks. In the case of couples, income and demographic differences account for $79 \%$ to $95 \%$ of the wealth model when we use the wealth model for whites to decompose the gap, depending on the specifics of how we measure permanent income. We explain only $25 \%$ to $28 \%$ when we use the black wealth model. When we use the ratio of wealth to permanent income as the measure of wealth we also explain a much larger fraction of the wealth gap using the coefficients for whites, although for couples and single females the fraction explained is smaller than in the wealth level case. Our median regression estimates parallel those for mean regression, but the percentages of the gap explained using the white wealth model are somewhat lower. We obtain similar results from separate analyses of the major components of wealth (main home equity, stocks/mutual funds and individual retirement accounts (IRAs), and the value of farms and businesses). All of these results reflect a finding that the wealth of whites is much more sensitive to income and demographics than the wealth of blacks. Although we typically explain more of the wealth gap than previous studies, perhaps because of our improved income and demographic variables, we confirm earlier results suggesting large disparities in the coefficients of the wealth models of whites and blacks.

The fact that we can explain most and in some cases all of the wealth gap using the white wealth model leads us to focus on a second question: Why are the wealth holdings of blacks less sensitive to differences in income and in demographics than the wealth holdings of whites? We use a theoretical model of intergenerational linkages to show that the legacy of discrimination could lead to a link between intergenerational transfers and income that is stronger for whites than for blacks. We empirically study this possibility by 
using data on siblings to relate differences among siblings in permanent and current income and demographics to differences wealth. Our study is the first (to our knowledge) sibling fixed-effects analysis of wealth accumulation behavior and is of independent interest. Using sibling comparisons largely neutralizes the effects of disparities between whites and blacks in inter vivos transfers and inheritances and provides a way of controlling for the effects of an adverse history on the relative position of blacks. With fixed effects coefficient estimates from the white sample we can explain $104 \%$ of the race gap in the wealth level, while the corresponding value based on the fixed effects model for blacks is only $49 \%$. Our sibling results confirm that wealth holdings are much less strongly related to income and demographic variables among blacks than among whites. This suggests that little of the difference between whites and blacks in the effect of income on wealth is due to differences in inter vivos transfers and inheritances. It is also consistent with evidence in Altonji \& Villanueva (2001) based on both the PSID and the survey of Asset and Health Dynamics (AHEAD) that the relationship between wealth at age 70 and permanent income is much weaker for blacks than for whites.

The other main possibilities are that savings rates or the rates of return to assets differ. We look at the combined effect of these two factors by estimating models for the growth in total wealth and wealth in particular categories as a function of permanent income and demographic factors, with and without sibling effects. In the case of couples, income and demographic factors explain $74 \%$ of the race gap in the growth of wealth when we use the growth model for whites but only $49 \%$ when we use the growth model for blacks. The discrepancy is even larger ( $84 \%$ versus $30 \%$ ) when we study growth in the wealth to permanent income ratio. These findings suggest that difference in savings behavior or rates of return on assets play a key role in explaining the wealth gap. However, the results are not entirely conclusive for reasons we discuss below. 
The paper proceeds as follows. In Section 2, we discuss the data used in the study, paying special attention to the measurement of permanent income. In Section 3 we present descriptive statistics on wealth, income, and other determinants of wealth. We present our econometric methods in Section 4. In Section 5 we turn to the basic set of results obtained from regression models of the wealth level that are commonly used in the literature. In Section 6 we present results for the ratio of wealth to permanent income and the $\log$ of wealth. In Section 7 we consider the use of higher order polynomials in income, median regression, alternative ways to measure permanent income, and alternative treatments of self employment and show that our main results are robust. In Section 8 we look in more detail at the wealth gap by evaluating the difference in wealth holding in a number of ways. We study the race gap in the components of wealth in Section 9. In Section 10, we look at the influence of income and demographics on wealth using sibling comparisons that are arguably free from bias due to inheritances and inter vivos transfers. We present growth models for wealth in Section 11 and provide conclusions and a research agenda in Section 12.

\section{Data}

The database is constructed from the main PSID files, the supplemental wealth files, the marriage history file, and the childbirth and adoption file. Wealth data were collected in 1984, 1989, and 1994. The PSID is based on a random sample of U.S. households in 1968 and a separate low income sample. The households were interviewed annually, providing many years of income data and long demographic histories for the panel members. We use both samples without weighting when estimating the wealth model, but use the family core weights to make our estimates nationally representative when computing decompositions of the wealth gap and, in some cases, descriptive statistics. We assign equal weight to each of the 1984, 1989, and 1994 surveys when we pool the data. 
The PSID contains a full set of variables only for household heads ("heads") and their spouses ("wives"). ${ }^{3}$ For this reason our analysis is based on persons who were either a head or a wife in one of the three years for which wealth surveys were conducted. To construct permanent income, we use information from for all survey years in which the individual was either a head or a wife. We also create a demographic history for each individual that describes past and present marriages and child bearing and rearing. The demographic variables are based in part on the PSID marriage history file and childbirth and adoption file.

Real non-asset family income is our measure of current income. We exclude asset income from our income measures because it may be affected by prior transfers and because it is a function of wealth. Wealth including home equity is our measure of wealth. It is important to point out to that Social Security wealth and pension wealth are excluded from our total wealth measure. These are important exclusions, and it would be desirable to incorporate them into future research. We also analyze the subcomponents main home equity (house value net of mortgage balance), stocks/mutual funds and IRAs, and wealth in farms/businesses. ${ }^{4}$

The log wealth (log current income) measures are constructed by taking the logarithm of the respective values truncated at $50(1,000) .^{5}$

\subsection{Measuring Permanent Income}

We use the panel data on individuals to construct the measures of permanent income. They are based on the regression model

$$
y_{i t}=X_{i t} \gamma+e_{i t},
$$

\footnotetext{
${ }^{3}$ The PSID convention is that the husband is the household head in a married couple.

${ }^{4}$ The other components of our total wealth measure are checking/savings, credit card, other real estate, vehicles, and other savings/assets. See Hurst et al. (1998) for descriptive statistics on these components.

${ }^{5} \mathrm{~A}$ data appendix and computer programs showing how the sample was constructed are available from the authors.
} 
where $y_{i t}$ is either the level or the logarithm of nominal non-asset family income of person $i$ in year $t$ and the vector $X_{i t}$ consists of a fourth-order polynomial in age (centered at 40), a marital status dummy, an indicator for children, the number of children, and a set of year dummies. Define $e_{i t}$ to be the sum of an individual-specific effect and an idiosyncratic error term, $e_{i t}=v_{i}+u_{i t}$, and assume that the serial correlation in $u_{i t}$ is sufficiently weak to be ignored in computing permanent income. We estimate the parameters of equation (1) from race- and gender-specific mean regressions using all observations in which the person was either a head or wife. Our measure of permanent income is the individual-specific effect $v_{i}$, estimated as the mean of the residuals from the regression for each person. This measure is basically a time-average of past, current, and future income adjusted for demographic variables and time.

The quality of the permanent income measures depends in part on the number of observations per individual that we average over. These range from 1 to $27 .{ }^{6}$ We dropped individuals with less than 4 years of observations from the subsequent analysis to ensure that transitory income and measurement error will have only a minor effect on our permanent income measures. ${ }^{7}$

A simple example can be used to illustrate the possible consequences of the difference between our measure of permanent income and the one used in previous studies. Let $i$ index individuals and $j$ demographic groups.

\footnotetext{
${ }^{6}$ For white males, the 10 th percentile of the numbers of observations used in the computation of the permanent income measure is 7 , the median is 20 , and the 90 th percentile is 27 . The corresponding numbers are 7,16 , and 27 for black males, 8,22 , and 27 for white females, and 7, 19, and 27 for black females, respectively. Between $15.2 \%$ and $32.7 \%$ of individuals in each race-gender group have been observed for 27 years, over the full course of the PSID.

${ }^{7}$ This restriction reduces the samples of white and black males by $1.2 \%$ and $2.4 \%$, respectively. The corresponding reductions are $0.9 \%$ and $1.6 \%$ for white and black females. Our basic results are not sensitive to requiring only 2 years of income data instead of 4 .
} 
Suppose wealth $W_{i}^{j}$ is a quadratic function of permanent income $y_{i}^{j}$,

$$
W_{i}^{j}=\alpha_{0}+\alpha_{1} y_{i}^{j}+\alpha_{2}\left(y_{i}^{j}\right)^{2}+\epsilon_{i}^{j}, \quad \alpha_{2}>0 .
$$

Suppose that the coefficients $\alpha_{0}, \alpha_{1}$, and $\alpha_{2}$ are the same for blacks and whites and that wealth is a convex function of permanent income. In this case the entire wealth gap is due to differences in the distribution of income. In line with previous studies, decompose $y_{i}^{j}$ into its expected value $y_{i}^{j *}$ given a set of predictors $X_{i}^{j}$ such as education and occupation and an error term $u_{i}^{j}, y_{i}^{j}=y_{i}^{j *}+u_{i}^{j}$. In this case,

$$
E\left(W_{i}^{j} \mid y_{i}^{j *}\right)=E\left(E\left(W_{i}^{j} \mid y_{i}^{j}\right) \mid y_{i}^{j *}\right)=\alpha_{0}+\alpha_{1} y_{i}^{j *}+\alpha_{2}\left(y_{i}^{j *}\right)^{2}+\alpha_{2} \operatorname{Var}\left(u_{i}^{j} \mid y_{i}^{j *}\right)
$$

and the stochastic regression function relating $W_{i}^{j}$ to $y_{i}^{j *}$ is

$$
\begin{aligned}
W_{i}^{j}= & \alpha_{0}+\alpha_{2} \operatorname{Var}\left(u_{i}^{j} \mid y_{i}^{j *}\right)+\alpha_{1} y_{i}^{j *}+\alpha_{2}\left(y_{i}^{j *}\right)^{2} \\
& +\alpha_{1} u_{i}^{j}+\alpha_{2}\left[\left(u_{i}^{j}\right)^{2}-\operatorname{Var}\left(u_{i}^{j} \mid y_{i}^{j *}\right)\right]+2 \alpha_{2} u_{i}^{j} y_{i}^{j *}+\epsilon_{i}^{j} .
\end{aligned}
$$

We have two points to make. First, the range of $y_{i}^{j *}$ is limited relative to $y_{i}^{j}$. This may force the researcher to choose a linear specification (as do Blau \& Graham (1990) and Menchik \& Jianakoplos (1997)), with

$$
W_{i}^{j}=a_{0}^{\prime}+a_{1}^{\prime} y_{i}^{j *}+\epsilon_{i}^{j} .
$$

If the distribution of $y_{i}^{j *}$ is "higher" for whites than blacks, then the income slope coefficient $a_{1}^{\prime}$ will be larger for whites and the intercept $a_{0}^{\prime}$ will be smaller. This may be shown using the auxiliary regression of $\left(y_{i}^{j *}\right)^{2}$ on $y_{i}^{j *}$, but the intuitive argument is straightforward. Suppose that all blacks have permanent income below some value $\bar{y}$ and that all whites have permanent income in excess of $\bar{y}$. Since wealth is a convex function of income, fitting a linear regression model for blacks will give a smaller slope coefficient, while fitting a linear model for whites will result in a larger slope coefficient. As a consequence, using either coefficient estimate to predict for the other group will underestimate true wealth holdings, leading one to underestimate the 
fraction of the group difference in wealth that is due to group differences in the income distribution. Second, if the mean of income is higher for whites than for blacks and if $\operatorname{Var}\left(u_{i}^{j} \mid y_{i}^{j *}\right)$ is an increasing convex function of $y_{i}^{j *}$ then the estimated slope and possibly the intercept of the wealth function will be higher for whites. When income is measured in levels the variance of our permanent income and current income measures are increasing, convex functions of the expectations of these variables conditional on variables such as education and occupation. This reinforces the first point.

Below we compare Blau \& Graham's (1990) and Menchik \& Jianakoplos's (1997) measure with our panel data based measure. We also experiment

with a separate measure of $y_{i}^{j}$ for each wealth survey using only income observations for that survey year and prior years.

\subsection{Outliers and Negative Wealth Values}

The wealth data contain a number of extremely high or extremely low observations. We eliminated extreme values by first estimating separate median regression models for blacks and whites using the specification described below, pooling the residuals from those models, and dropping the observations corresponding to the bottom $0.5 \%$ and top $0.5 \%$ of the residuals. The procedure was conducted separately for couples, single men, and single women. We used separate trimming procedures for the level, ratio, and log models. Eliminating the outliers dramatically reduced the sampling error of our mean regression models, at the likely cost of some bias. (The reported standard errors are also probably understated a bit because they ignore sampling variation in the trimming process.) Our main findings are not very sensitive to excluding the outliers but standard errors are dramatically affected, and the size of the gap between whites and blacks is reduced somewhat. All results are for the trimmed sample unless noted otherwise. 


\section{Race Differences in Wealth, Income, and Demo- graphics}

We begin by providing some basic facts about race differences in wealth and the key income and demographic variables in our analysis. To save space, we present statistics for the pooled sample of observations for 1984, 1989, and $1994 .^{8}$

Table 1 provides the mean and standard deviation for wealth $(W)$ and its major components, for the wealth/permanent income ratio $(W / y)$, and for $\log$ wealth $(\ln W)$. It also reports statistics for log income, current income, and permanent income in 1989 US $\$$. Outliers are included so that the numbers will better reflect population totals. Table A1 reports corresponding values for the trimmed sample. There are separate columns for white couples, black couples, single white males, black white males, single white females, and single black females. A single person may be in multiple samples if their marital status changes over time. In the case of couples, the mean (standard deviation) of wealth is $53,472(140,253)$ for blacks and $211,602(627,938)$ for whites, a ratio of 0.25 . The race gap for family income is much smaller with a mean of 30,153 $(19,985)$ for blacks and 41,519 $(43,788)$ for whites, a ratio of 0.73 . This is reflected in our permanent income measures, which have a mean of 32,450 (12,747) for black heads and 46,949 $(20,613)$ for white heads. The permanent income values are 30,086 $(13,681)$ and 43,097 $(22,636)$ for black and for white wives. The black/white ratios of permanent income are about 0.70. Moreover, the distributions for current and permanent income are much more concentrated than the distributions

\footnotetext{
${ }^{8}$ The ratio of black to white wealth remains roughly constant over time for couples and single females but increases dramatically from 0.14 in 1984 to 0.33 in 1994 for single men. With respect to permanent income black couples seem to lose some ground (the ratio is falling from 0.72 for both heads and wives in 1984 to 0.65 for heads and 0.67 for wives in 1994). Finally, the ratio of current income drops from 0.81 in 1984 to 0.67 in 1994 for females.
} 
for wealth. The much larger racial disparity in wealth levels is reflected in the wealth/permanent income ratios. The mean wealth/permanent income ratio for black couples is 1.80 (4.36), which is only $37 \%$ of the value of 4.87 (11.26) for white couples.

In Table 1 we also report descriptive statistics for main home equity, the value of a farm and business, and the value of stocks, mutual funds, and IRAs. For each component we report the mean and standard deviation for the households who have nonzero values as well as the overall mean and standard deviation when including the zero values. The race gap in home equity is smaller than the gap in total wealth. With zero values included, the mean of home equity is $25,293(52,647)$ for black couples, which is $43 \%$ of the value of $58,462(76,053)$ for white couples. In contrast, black couples hold only 4,073 $(22,080)$ in stocks, mutual funds, and IRAs, which is only $15 \%$ of the corresponding mean value of $27,589(188,793)$ for whites. Only $15 \%$ of black households hold wealth in this category, while $40 \%$ of white households do.

The black self-employment rate is only about one third of the white selfemployment rate, and this ratio has been relatively constant for the past 70 years (Fairlie \& Meyer 1997). Given this fact, one would expect the value of farms and businesses to be much smaller for blacks than for whites. The data confirm this. Only $4 \%$ of black couples have assets in a farm or business, while $20 \%$ of white couples have such assets. Including the zero values, black couples hold an average of 2,689 $(43,853)$ in farms or businesses, which is only $7 \%$ of the mean of $39,149(259,850)$ for whites.

The situation for single heads of household mirrors the one for couples. In the case of single women, the mean of wealth is $15,099(40,543)$ for blacks and $70,599(208,029)$ for whites, a ratio of 0.21 . The race gap for income is again much smaller with a mean of $10,590(8,844)$ for blacks and 14,618 $(26,781)$ for whites, a ratio of 0.72 . The mean of permanent income is 25,045 $(7,872)$ for blacks and $38,939(13,731)$ for whites. ${ }^{9}$

\footnotetext{
${ }^{9}$ The mean of permanent income for single female heads exceeds the mean of current
} 
In Table 2 we present the definitions and descriptive statistics of demographic variables that influence wealth. The values for the trimmed sample are very close to the values for the full sample and are omitted for brevity. The means for many of the variables differ considerably across races. Because housing prices vary across regions, and a much higher proportion of blacks live in the south, we control for region and residence in a Standard Metropolitan Statistical Area (SMSA) in our analysis. In the case of couples, the average umber of children currently living in the family unit is higher for blacks (1.21) than for whites (0.92) although the number of dependents is similar ( 0.29 for blacks and 0.25 for whites). The difference in the total number of own or adopted children is even bigger, with an average of 2.86 (2.85) for black heads (wives) and 2.43 (2.42) for black heads (wives). This points to the potential importance of controlling not only for current demographics but also for demographic histories.

Blacks describe themselves as being in poor or fair health more often than whites. ${ }^{10}$ Whites are better educated than blacks, with almost three times as many whites holding a college degree and two times as many whites holding advanced or professional degrees as blacks.

Table 2 confirms a large literature showing that self-employment rates are much higher for whites than blacks. (In the case of couples that rates are with 0.05 (0.03) for black heads (wives) and 0.18 (0.08) for white heads

income dramatically. In part, this reflects the fact that our income measure includes years in which the individual was married, although the income observations that go into permanent income are adjusted for the effects of marital status. Since the average age for black single females is about the same as for black couples while the average age for white females is higher than that for white couples, the differences in permanent income do not seem to reflect the earlier position of singles in the life-cycle. Instead, they seem to be due to inherent differences in earnings potentials across demographic groups. Similar observations hold for single men.

${ }^{10}$ Interestingly, Smith (1995) finds that "healthier households are wealthier ones" for both blacks and whites. Hence, controlling for health status helps to explain the wealth gap. The question of causality, however, is tricky. 
(wives). As we show in Section 7.4, this variable has a substantial association with wealth, although the direction of causality is not clear.

\section{Econometric Models and Wealth Decompositions}

Let $i=1, \ldots, N^{j}$ index individuals or couples and $j$ demographic groups, where $j$ is $b$ for blacks and $w$ for whites. Let $W_{i}^{j}$ denote wealth, $Y_{i}^{j}$ a vector of income variables (including current income $y_{i t}$ and permanent income $\left.y_{i}\right)$, and $X_{i}^{j}$ a vector of demographic variables. Since we have panel data on wealth, a number of variables in addition to $y_{i t}$ depend on the calendar year $t$ as well as $i$, but we leave the time subscript implicit.

Our basic model specifies the level of wealth to be linear in the income and demographic variables and is given by

$$
\begin{aligned}
W_{i}^{w} & =\alpha_{0}^{w}+Y_{i}^{w} \alpha^{w}+X_{i}^{w} \beta^{w}+\epsilon_{i}^{w}, \\
W_{i}^{b} & =\alpha_{0}^{b}+Y_{i}^{b} \alpha^{b}+X_{i}^{b} \beta^{b}+\epsilon_{i}^{b}
\end{aligned}
$$

where $\alpha_{0}^{w}, \alpha^{w}$, and $\beta^{w}$ are the regression intercept and slope parameters for whites, $\epsilon_{i}^{w}$ is the error term, and $\alpha_{0}^{b}, \alpha^{b}, \beta^{b}$, and $\epsilon_{i}^{b}$ are the corresponding parameters and error term for blacks. Separate sets of regressions are specified for single males, single females, and married couples, so the slopes and intercepts depend on sex and marital status as well as on race. The observations are pooled the 1984, 1989, and 1994 surveys. We use indicator variables to control for differences over time.

We report both mean regression (OLS) and median regression results and so alternatively define $\alpha_{0}^{j}+Y_{i}^{j} \alpha^{j}+X_{i}^{j} \beta^{j}$ to be the conditional mean or the conditional median regression function. There are a number of reasons why median regression estimates are of interest. First, one may simply be more interested in the median of wealth for persons with a given set of characteristics than in the mean of wealth for the. Second, the skewness and fat tails of the wealth distribution suggest that it may be easier to estimate conditional medians (Koenker \& Bassett 1978, Narula \& Wellington 1982). 
Given that the level of wealth is used as the dependent variable, equations (2) and (3) impose additive separability between the income and demographic variables. We work with the levels of wealth because much of the public discussion is couched in terms of levels and because of the large fraction of the population with negative wealth reports. However, we doubt that there is any sensible specification of consumption preferences over the life course, with or without bequests, that would imply that the conditional mean of the level of wealth is additively separable in income and demographic variables. It implies, for example, that the effect of having another child on wealth does not depend on permanent income, which seems unlikely. Consequently, in Section 6 we also work with the $\log$ of wealth and the ratio of wealth to permanent income of the head as the dependent variable. The log model implicitly allows for multiplicative interactions in the equation for the level of wealth. However, the log specification is poorly suited as a wealth model because wealth holdings are frequently negative or close to zero. The ratio specification avoids this problem and implies that the effects of demographic variables are proportional to permanent income.

We evaluate the explanatory power of our models using a slightly modified regression decomposition (Blinder 1973, Oaxaca 1973) that allows for median regression models and accommodates the use of population weights in computing the wealth gap. Let $\left\{\omega_{i}^{j}\right\}_{i=1}^{N^{j}}$ denote a set of population weights such that $\omega_{i}^{j}>0$ and $\sum_{i=1}^{N^{j}} \omega_{i}^{j}=1 .{ }^{11}$ Let $Z_{i}^{j}=\left(1, Y_{i}^{j}, X_{i}^{j}\right)$ and $\theta^{j}=\left(\alpha_{0}^{j},\left(\alpha^{j}\right)^{\prime},\left(\beta^{j}\right)\right)^{\prime}$. Equations (2) and (3) can be written as

$$
W_{i}^{j}=Z_{i}^{j} \theta^{j}+\epsilon_{i}^{j}, \quad j=b, w,
$$

where the definition of $\theta^{j}$ and $\epsilon_{i}^{j}$ depends on whether we use median or mean regression. Let $\hat{W}_{\bullet}^{j}=\sum_{i=1}^{N^{j}} \omega_{i}^{j}\left(Z_{i}^{j} \hat{\theta}^{j}\right)$ denote the mean of the predictions for individuals in demographic group $j$, where $\hat{\theta}^{j}$ is an estimate of $\theta^{j}$. For a

\footnotetext{
${ }^{11}$ We take $\left\{\omega_{i}^{j}\right\}_{i=1}^{N^{j}}$ to be the family core weights that are supplied with each wave of the PSID. We assign equal weight to each of the 1984, 1989, and 1994 surveys when we pool the data.
} 
given family type, e.g. couples, write

$$
\begin{aligned}
\hat{W}_{\bullet}^{w}-\hat{W}_{\bullet}^{b} & =\sum_{i=1}^{N^{w}} \omega_{i}^{w}\left(Z_{i}^{w} \hat{\theta}^{w}\right)-\sum_{i=1}^{N^{b}} \omega_{i}^{b}\left(Z_{i}^{b} \hat{\theta}^{b}\right) \\
& =\left\{\sum_{i=1}^{N^{w}} \omega_{i}^{w}\left(Z_{i}^{w} \hat{\theta}^{b}\right)-\sum_{i=1}^{N^{b}} \omega_{i}^{b}\left(Z_{i}^{b} \hat{\theta}^{b}\right)\right\}+\left\{\sum_{i=1}^{N^{w}} \omega_{i}^{w}\left(Z_{i}^{w} \hat{\theta}^{w}\right)-\sum_{i=1}^{N^{w}} \omega_{i}^{w}\left(Z_{i}^{w} \hat{\theta}^{b}\right)\right\} .
\end{aligned}
$$

The first term measures what the contribution to the wealth gap of race differences in the explanatory variables would be if the relationship between wealth and the explanatory variables was given by $\hat{\theta}^{b}$, the coefficient vector for blacks. The second term evaluates contribution to the wealth gap of differences between whites and blacks in the wealth coefficients using the distribution of the explanatory variables for whites. The first term thus represents the part of the wealth gap $\hat{W}_{\bullet}^{w}-\hat{W}_{\bullet}^{b}$ that is "explained" by differences between blacks and whites in the explanatory variables, while the second term represent the unexplained part of the wealth gap. ${ }^{12}$ We contrast the decomposition based on the above equation with the decomposition

$\hat{W}_{\bullet}^{w}-\hat{W}_{\bullet}^{b}=\left\{\sum_{i=1}^{N^{w}} \omega_{i}^{w}\left(Z_{i}^{w} \hat{\theta}^{w}\right)-\sum_{i=1}^{N^{b}} \omega_{i}^{b}\left(Z_{i}^{b} \hat{\theta}^{w}\right)\right\}+\left\{\sum_{i=1}^{N^{b}} \omega_{i}^{b}\left(Z_{i}^{b} \hat{\theta}^{w}\right)-\sum_{i=1}^{N^{b}} \omega_{i}^{b}\left(Z_{i}^{b} \hat{\theta}^{b}\right)\right\}$,

which uses the coefficient vector for whites to measure the part of the wealth gap that is explained by differences in income and demographics.

Suppose for the moment that we assign equal weights to all observations, $\omega_{i}^{j}=1 / N^{j}$. In the context of a mean regression model, this implies $\hat{W}_{\bullet}^{j}=\bar{W}_{\bullet}^{j}$, where $\bar{W}_{\bullet}^{j}$ denotes the sample mean, because $\sum_{i=1}^{N^{j}} \hat{\epsilon}_{i}^{j}=0$ by construction. In general, this is not true for median regression models, so the sample median differs from the mean of the conditional medians. Furthermore, because we estimate the model parameters without weighting but weight the observations when performing decompositions, $\sum_{i=1}^{N^{j}} \omega_{i}^{j} \hat{\epsilon}_{i}^{j}$ differs from zero even for mean regression models.

\footnotetext{
${ }^{12}$ DiNardo, Fortin \& Lemieux (1996) discuss ways of decomposing group differences into the effects of observed characteristics and unobserved differences in the context of nonparametric statistical models.
} 


\section{Basic Results}

In this section we present estimates of equations (2) and (3) as well as decompositions of the race gap in the wealth level $W$ into a component explained by differences in income and demographic variables and an unexplained component that measures the part of the wealth gap that remains after conditioning on income and demographics. In Section 5.1 we discuss the findings for couples and in Section 5.2 we consider single men and single women.

\subsection{Couples}

In the case of couples the controls for income and earnings capacity $Y_{i}$ are current family income, permanent family income of the husband, permanent family income of the wife's permanent income, the squares of current income, head's permanent income, wife's permanent income, and the products of current income with the head's and the wife's permanent income. ${ }^{13}$ The demographic controls are listed in Table 2. $X_{i}$ contains region dummies and a dummy for residence in an SMSA, six education dummies for the husband and six for the wife, the wife's work hours in the previous year ${ }^{14}$, dummies for whether the husband is self employed and for whether the wife is self employed, and dummies for whether the wife's health is fair or poor and whether the husband's health is fair or poor. The demographic controls also

\footnotetext{
${ }^{13}$ Recall that the permanent family incomes of husbands and wives who have been married for many years are based on the same family income data and are essentially the same. We include them separately to allow for the fact that family earnings of the husband and wife prior to marriage may have different effects on wealth in marriage. We obtain very similar wealth decompositions when we use the average of the husband's and the wife's permanent family incomes.

${ }^{14}$ We include the wife's work hours because it has been used in some of the previous studies, although there are some obvious endogeneity issues that may lead to different biases for whites and blacks. The decompositions in Table 3 below are not very sensitive to dropping it.
} 
include fourth-order polynomials in the age of the husband and in the age of the wife (centered at 40), the number of siblings of the head, a dummy equal to 1 if there are children under 18 in the family unit and 0 otherwise, the number of children under 18 in the household, controls for whether the household head has dependents outside of the family unit and the number of dependents outside the family unit. We also include controls for the number of marriages of the head, the respective number for the wife, the tenure of the current marriage, the number of children of the head, and the number of children of the wife. Finally, we include year dummies for the 1984 and the 1994 surveys.

Our choice of variables is driven largely by previous studies of wealth differences, although our specifications of income and marriage and fertility histories are more elaborate. We chose to start with and stick to a fairly broad set of variables rather than "fish around" for a shorter list of variables that are statistically significant. Our main focus is on the wealth decompositions rather than the wealth models themselves, and so we do not discuss the coefficients of the individual variables in any detail. The coefficient estimates can be found in Table A2.

The top row of Panel A in Table 3 reports decompositions of the wealth level $W_{i}$ for couples. The mean (standard error) of the wealth gap is $116,795(4,535) .{ }^{15}$ Using the coefficient estimates for the white equation $\hat{\theta}^{w}=\left(\hat{\alpha}_{0}^{w},\left(\hat{\alpha}^{w}\right)^{\prime},\left(\hat{\beta}^{w}\right)^{\prime}\right)^{\prime}$ we find that the white/black difference in the explanatory variables explains $92,589(4,855)$ of the gap, or $79 \%$. We obtain strikingly different results when we use the wealth equation for blacks. Using $\hat{\theta}^{b}=\left(\hat{\alpha}_{0}^{b},\left(\hat{\alpha}^{b}\right)^{\prime},\left(\hat{\beta}^{b}\right)^{\prime}\right)^{\prime}$ we find that only $29,009(4,509)$ or $25 \%$ of the wealth gap is explained by differences in the explanatory variables. This

\footnotetext{
${ }^{15}$ This value is $\hat{W}_{\bullet}^{w}-\hat{W}_{\bullet}^{b}$, the difference in the weighed mean of the predictions of wealth for whites and blacks respectively based on the regression model. As we pointed out in Section $4, \hat{W}_{\bullet}^{w}-\hat{W}_{\bullet}^{b}$ need not be exactly equal to $\bar{W}_{\bullet}^{w}-\bar{W}_{\bullet}^{b}$, the difference in the weighted sample means wealth for whites and blacks. From Table A1, the latter figure is $115,228(=187,589-52,361)$.
} 
large discrepancy between the white and the black wealth models in the degree to which racial differences in the distributions of the income/human capital and demographic variables can explain the gap in wealth levels is a key theme in our analysis. The discrepancy reflects the fact that wealth differences among blacks are much less sensitive to differences in income and demographics than wealth differences among whites.

To better understand race differences in the parameters of the wealth equations, it is instructive to consider the income coefficients. The coefficients on the terms of the income polynomial are hard to interpret directly. At the bottom of Table A2 we report the effect of a unit increase in $y_{i t}$ and $y_{i}$ at the sample mean (pooled over race) of $y_{i t}$ and $y_{i}$. The effect of a unit increase in $y_{i t}$ is .64 for whites and .69 for blacks. The effect of increasing the husband's (wife's) permanent income by one dollar is 1.04 (1.98) for whites and -.02 (.91) for blacks. The combined effect of increasing $y_{i t}, y_{i}$ of the husband, and $y_{i}$ of the wife by one dollar is 3.66 for whites and 1.58 for blacks. The key point to notice about these derivatives is that they tend to be much larger for whites than for blacks. The same is true for single males and single females and when we evaluate the derivatives at 0.5 of the sample mean and at 1.5 of the sample mean. However, the gap in the sensitivity of wealth to income is substantially higher above the mean than below the mean. ${ }^{16}$

Although there is some variation across variables (in part because of sampling error), the coefficients on the other variables in the model also tend to be larger in absolute value for whites than for blacks. To establish this

\footnotetext{
${ }^{16}$ The effect of a unit increase in current income and permanent income is 2.04 for whites and 2.04 for blacks when current income and permanent income are 0.5 of the mean for the pooled sample, which is the only exception to the rule of larger marginal effects for whites. At 1.5 of the mean the values are 5.28 for white couples versus 1.12 for black couples. The values for single white males and single black males are 1.00 versus 0.46 at 0.5 of the mean, 1.55 versus .39 at the mean, and 2.11 versus 0.31 at 1.5 times the mean. The values for single white females and single black females are 1.95 versus 0.82 at 0.5 of the mean, 1.75 versus .68 at the mean, and 1.55 versus 0.54 at 1.5 times the mean.
} 
point, we computed the component $Y_{i} \hat{\alpha}^{j}$ of the index $Z_{i} \hat{\theta}^{j}$ that corresponds to the income variables for $j=w$ and $j=b$ for each observation in the combined sample of blacks and whites. The regression of $Y_{i} \hat{\alpha}^{b}$ on $Y_{i} \hat{\alpha}^{w}$ and a constant is 0.284 with an OLS standard error of 0.0026. A similar regression involving the $X_{i} \hat{\beta}^{w}$ and $X_{i} \hat{\beta}^{b}$ indexes of the demographic variables shows that differences in demographics have a stronger association with wealth levels for whites than for blacks. The slope coefficient in a regression of $X_{i} \hat{\beta}^{b}$ on $X_{i} \hat{\beta}^{w}$ and a constant is 0.354 with an OLS standard error of 0.0016. When one forms the index using both income and demographic variables and regresses $Z_{i} \hat{\theta}^{b}$ on $Z_{i} \hat{\theta}^{w}$ and a constant the slope coefficient is .305 (.002). The patterns are very similar for single women and single men, with the exception that for single men the coefficient on the index of income variables is close to 1 . In Section 10, we will explore these differences in more detail using persons from the same family to control for the possibility that race-related differences in inheritances that are correlated with income and demographics drive this finding.

\subsection{Single Men and Single Women}

The second and third rows of Panel A of Table 3 report wealth decompositions for single men and single women who are heads of households. The regression models used are reported in Tables A3 and A4, respectively. These models are the same as the models for couples except that spouse variables are excluded.

For single women the race gap in wealth is $46,575(2,204)$. The model for the white sample implies that single black women would have 48,149 $(4,447)$ or $103 \%$ of the wealth that white women hold if they had the same income and demographics as whites. However, the wealth model for blacks tells a completely different story. Only $15,567(4,163)$ or $33 \%$ of the total gap is attributable to income and demographics.

Using the coefficient estimates for whites we find that single black men 
would have $20 \%$ more wealth than single white men if they had the same income and demographics as whites. This result, like the result for single females, suggests that the large wealth gap is simply a reflection of racial differences in income streams, human capital variables, and current and past demographic variables. However, we again obtain very different results when we use the wealth model for blacks to perform the wealth decomposition. In this case only $12,405(2,154)$ or $31 \%$ of the total gap of $40,365(2,613)$ is attributable to income and demographics.

In summary, we find that most or all of the race gap in the wealth level for single men and single women and a substantial portion of the gap for married couples would disappear if blacks and whites had the same distribution of income and demographic variables and the white wealth equation held for blacks. However, the wealth models for blacks exhibit much less income sensitivity, indicating that both the race gap in the income and demographics and race differences in the distribution of wealth conditional on income and demographic variables play important roles in the gap in wealth levels. ${ }^{17}$

\footnotetext{
${ }^{17}$ In their wide ranging study of wealth accumulation Hurst et al. (1998) use the PSID to examine race differences in the level of wealth. They pool married couples, single males, and single females, exclude nonlinear permanent income terms, and use a much simpler set of control variables than we do. Because they pool whites and blacks and only allow the intercept of the wealth model to depend on race, they do not address the question of differences in the form of the wealth function. They find that intercept for blacks is 25,514 below that for whites. Using this value and the mean differences in wealth in 1989 and 1994 for blacks and whites reported in their paper implies that income and demographic factors explain about $90 \%$ of the wealth gap. Because there are more whites than blacks and whites have more dispersed incomes, one would expect the coefficients of the pooled model to be closer to those for whites. When viewed in this light, Hurst et al.'s (1998) findings are broadly consistent our findings based on the white sample for the different demographic groups.
} 


\section{Results for $W / y$ and $\ln W$}

In Panel B of Table 3 we present results using the ratio of wealth to permanent income $W / y$ as the wealth measure. As noted above $W / y$ is probably a better specification than the level specification because it allows for the effects of income and demographic characteristics to interact. The use of $W / y$ also avoids the problems posed by the large number of negative or zero values for wealth for a log specification, and the estimates are easier to interpret. The results largely confirm our findings based on $W$. For white couples, the mean of the predicted value of $W / y$ is $4.18(0.08)$, while the corresponding value for blacks is $1.74(0.10)$. The total gap is $2.44(0.13)$. Demographic and income characteristics account for $57 \%$ of this when we use white coefficients but only $12 \%$ when we use the black coefficients. In the case of single males the total gap is $0.70(0.07)$. Demographic and income characteristics explain $119 \%$ of the gap when we use the white coefficients but only $27 \%$ when we use the black coefficients. In the case of single single females, the corresponding numbers are $78 \%$ and $45 \%$. Overall, the relative explanatory power of the regression models for blacks is higher when $W / y$ is the explanatory variable than when $W$ is the explanatory variable. However, the results for $W / y$ are generally consistent with the results for levels.

In Panel $\mathrm{C}$ of Table 3 we report decompositions for $\ln W$. The explanatory variables are the same as for the level and ratio models except that we substitute the log of current income and the log of permanent income for the levels of these variables. For couples the mean of the log wealth gap is 1.51 (0.06). Using the wealth model for whites we can explain $77 \%$ of this gap. Using the wealth model for blacks we can explain $72 \%$.

For single women, the mean of the gap in the log of wealth is 2.57 (0.08). Using the white equation the portion of the gap that is explained by income and demographics is $1.68(0.10)$ or $65 \%$ of the total. The explained gap based on equation for blacks is also $65 \%$ of the total gap.

For single men the gap in log wealth is $2.00(0.10)$. Using the white equa- 
tion the portion of the gap that is explained by income and demographics is $1.71(0.10)$, or $85 \%$ of the total. The explained gap based on the equation for blacks is $1.53(0.12)$, or $76 \%$ of the total. In percentage terms, the explanatory variables account for more of the race gap in log wealth for single men than for either single women or couples. The $85 \%$ figure when the log wealth model for whites is used is particularly striking, and well in excess of the figures reported by Blau \& Graham (1990).

Overall, income and demographics explain a substantial part of the wealth gap between whites and blacks. The results based upon the white $\log$ model are less dramatic than the results for the white level wealth itself, and the portion of the gap explained using the black model is much larger in case of the log model than in case of the level model. However, this disparity between the log results and the results for levels and ratios should not be overstated. In particular, since the model for $\ln W$ implies a multiplicative model for $W$, the huge race gap in the mean of log wealth together with the substantial fraction of the gap that is not explained by income and demographics implies that the response of wealth to income variables and demographic variables is much smaller for blacks than for whites. This point comes through most starkly in the case of single females. From Panel C of Table 3 the total gap in the mean of $\ln W$ is 2.57. The regression models for whites and blacks both explain $65 \%$ of this gap, leaving an unexplained gap of $.90(=.35 \times 2.57)$. Consider the most extreme case in which the slope coefficients of the log models for whites and blacks are equal and all of the unexplained gap is due to the intercept. Assume that the distribution of the errors in the log models do not depend on race, income, and demographics. Then for whites the derivative of wealth with respect the income and demographics will be $e^{.90} \approx 2.46$ times the corresponding derivative for blacks. ${ }^{18}$ Consequently, the evidence based upon the log models is broadly consistent

\footnotetext{
${ }^{18}$ If $\ln W_{i}^{b}=Z_{i}^{b} \theta+\epsilon_{i}^{b}$ and $\ln W_{i}^{w}=.90+Z_{i}^{b} \theta+\epsilon_{i}^{b}$, then $E\left(W_{i}^{b} \mid Z_{i}^{b}\right)=e^{Z_{i}^{b} \theta} E\left(e^{\epsilon_{i}^{b}}\right)$ and $E\left(W_{i}^{w} \mid Z_{i}^{w}\right)=e^{.90} e^{Z_{i}^{w} \theta} E\left(e^{\epsilon_{i}^{w}}\right)$.
} 
with the evidence for levels and ratios.

\section{Results for Alternative Specifications and Esti- mation Procedures}

\subsection{Third Order Polynomials in Income}

When we add third powers in current and permanent income, we explain $83 \%, 119 \%$, and $104 \%$ of the wealth gap in levels for couples, single males and single females, respectively, using the white equation. These estimates are close to the corresponding values in Panel A of Table 3 for the quadratic specification $-79 \%, 120 \%$, and $103 \%$.

When we use the cubic specification with the black sample, the corresponding values for couples, single males and single females are $-4 \%, 43 \%$, and $580 \%$. However, the OLS standard error on the predicted value of the level of wealth for single white females using the black wealth model is 86,837 . Evidently, differences in income distributions across groups in combination with small sample sizes leads to noisy results when we estimate the cubic model for black women and use it to make predictions for whites. (The corresponding standard errors are 2,538 for single white males and 9,064 for white couples.)

When the dependent variable is $W / y$, we explain $62 \%, 124 \%$, and $77 \%$ of the wealth gap for the three samples using a cubic specification of the white wealth model. These values are close to the estimates in Table 3 panel $\mathrm{B}$ based on the quadratic specification. We explain $-13 \%, 27 \%$, and $374 \%$ of the gap in $W / y$ using the black wealth model. The value of $374 \%$ for single women again reflects a very large and very imprecise predicted value of $W / y$ for white single women when we use the cubic specification of the black wealth model.

In summary, our decompositions based on the white wealth model are not affected very much by using a cubic specification. However, the decom- 
positions based on the black wealth model become quite imprecise in the case of single women. For this reason, we use the quadratic specification for most of the analysis.

\subsection{Median Regression Models}

We measure the wealth gap as the population-weighted average of the difference between the conditional median of wealth based on the median regression for the white sample and the distribution of characteristics in the white sample and the median regression and distribution of characteristics for the black sample, $\hat{W}_{\bullet}^{w}-\hat{W}_{\bullet}^{b}$. We refer to this as the gap in the conditional median of wealth. Table 4 presents the decompositions. The control variables are the same as in the mean regression models. In the case of couples, the total gap in the median is estimated to be $84,794(2,824)$, which compares to a gap in the mean of wealth of $116,795(4,535)$. The total gap in $W / y$ is 1.81 (0.07) for medians and 2.44 (0.13) for means. The gaps in the median of $\ln W$ and the mean of $\ln W$ are more similar (1.36 (0.05) versus $1.51(0.06)$ ), which is not surprising given that log transformation reduces the skewness of the wealth distribution.

In the case of couples the income and demographic variables account for $68 \%$ of the wealth gap in the average of the conditional medians if the median regression function for whites is used (Panel A). In contrast, the median wealth regression for blacks implies that characteristics account for only $22 \%$ of the gap in the conditional median of wealth. For single men the white median regression implies that $85 \%$ of the gap is explained, while the black median regression implies a figure of only $41 \%$. The corresponding figures for females are $74 \%$ and $42 \%$. Overall, income and demographics account for a somewhat smaller percentage of the race gap in the conditional median of the wealth level than in the conditional mean when the white model is used, particularly in the case of single men and single women. When the median wealth model for blacks is used, the percentage explained is slightly 
lower than the corresponding value for the conditional mean in the case of couples but higher for single men and women.

The results for $W / y$ in Panel $\mathrm{B}$ of Table 4 are similar to the results for levels, except that the portion of the gap explained by the white median regression model is substantially smaller for both couples and single females.

The results for $\ln W$ in Panel $\mathrm{C}$ of Table 4 are basically similar to the results based on mean regression and also imply that the wealth of whites is much more sensitive to income and demographics than the wealth of blacks once the implications of the log specification and the large unexplained gap are taken into account.

\subsection{Alternative Measures of Permanent Income}

We have performed the decompositions in Table 3 using a measure of permanent income that is based upon family income prior to survey year. In this case, the permanent income measures vary across surveys for the same individual. It makes sense to exclude future earnings to the extent that individuals are highly uncertain about them and to the extent that income shocks are fairly persistent. We typically explain as much or more of the wealth gap when we use the backward-looking permanent income measure than when we use our usual measure. For example, for couples, single men and single women income and demographic characteristics account for $95 \%$, $119 \%$ and, $112 \%$ of the gap in wealth, respectively, when the white wealth model is used. For the three groups they explain only $28 \%, 36 \%$, and $34 \%$ of the gap when the black model is used.

We have also used the methodology of Blau \& Graham (1990) and Menchik \& Jianakoplos (1997) to measure permanent income. For couples, the observables explain $50 \%$ of the gap in $W$ based on the white wealth model and $0 \%$ based on the black model. For single females the percentages are $84 \%$ and $35 \%$. For single men the percentages are $63 \%$ and $50 \%$. The percentages based on the wealth model for whites are well below those in 
Table 3 or those using lagged income data to construct permanent income. The results indicate that the use of panel data to construct permanent income measures increases the percent of the gap in wealth levels that can be attributed to differences in income and demographic characteristics. Not surprisingly, we experienced difficulties with the Blau \& Graham's (1990) approach when we allow for nonlinear effects of permanent income.

For $W / y$ we explain a larger percentage of the gap using Blau \& Graham's (1990) permanent income measure and the white wealth model for couples $(92 \%)$. This value is substantially above the fraction explained using our panel data based measures of permanent income $(57 \%)$, but the corresponding percentage using the black wealth model is $-18 \%$ (compared to $12 \%$ ). (Note that for these estimates we use our panel data based measure of permanent income when constructing $W / y$ even though we use Blau \& Graham's (1990) measure for the explanatory variables.)

\subsection{Treatment of Self Employment}

We have already discussed the race gap in business wealth as well as the race gap in self-employment rates. If causality runs mainly from self employment to wealth, then it is desirable to control for self employment in the analysis, especially to the extent that the effects of past discrimination on the selfemployment rate of blacks lingers today (see for example the discussion in Oliver \& Shapiro (1997)). However, some studies of the race gap in self employment attribute part of the self-employment gap to a lack of financial capital. If the causality runs from wealth to self employment, then it is less clear that self employment should be controlled for.

The coefficient on self employment is quite substantial in the wealth models. In the case of white couples, the coefficients on the dummies for self employment of the head and self employment of the spouse are 150,010 and 47,916 respectively in the model for wealth levels. The corresponding coefficients in the model for blacks are 57,415 and -3,784. The combina- 
tion of a much higher self-employment rate for whites (.18 versus .05 in the case of heads and .08 versus .03 in the case of spouses) and a much stronger association between self employment and wealth for whites make a substantial contribution to the race gap in wealth. When we remove the self-employment indicators from the wealth model for couples, the fraction of the gap in $W$ explained using the white wealth model declines from $79 \%$ to $64 \%$. The fraction of the gap in $W / y$ explained declined from $57 \%$ to $41 \% .{ }^{19}$ Differences in self-employment rates make a much smaller contribution to the wealth gap for single males and single females. The percentage of the gap in $W$ explained using the white wealth model is $114 \%$ for males and $100 \%$ for females even when self employment is excluded. Overall, the evidence suggests that race differences in self-employment patterns are a significant part of a full explanation of black/white wealth differences, although causality is ambiguous.

\section{Alternative Samples and Evaluation Points for the Wealth Gap}

Thus far we have reported decompositions of the wealth gap using the full distribution of the income and demographic variables for the white and the black populations. In this section we consider three other comparisons. Our chief motivation is to explore the possibility that a lack of overlap between the white and black samples is leading to unreliable estimates, particularly when the black coefficients are used, because we are extrapolating too far out of sample.

First, we performed decompositions at the sample means of the explanatory variables for whites and the sample means for blacks. Using the white coefficient estimates the differences in explanatory variables account for

\footnotetext{
${ }^{19}$ The corresponding values with and without self employment when the black wealth models are used are $25 \%$ and $19 \%$ for $W$ and $12 \%$ and $5 \%$ for $W / y$.
} 
$115 \%, 99 \%$, and $114 \%$ of the gap in the wealth level $\mathrm{W}$ for single men, single women, and couples, respectively. Using the black coefficients the differences in the means of the explanatory variables only account for $15 \%$, $20 \%$, and $42 \%$ of the wealth gap. In the case of $W / y$ the difference in income and demographic variables accounts for $108 \%, 83 \%$, and $101 \%$ of the race gap in $W / y$ for single men, single women, and couples, respectively, when the white wealth model is used, but only $12 \%, 22 \%$, and $34 \%$ when the black model is used. The decompositions are broadly consistent with the results in Table 3 using the full distribution, although in the case of couples the explanatory power of the white wealth model is substantially larger for both wealth measures. We continue to find a large difference between the black and white equations in the role assigned to differences in characteristics.

Second, we tried the novel approach of selecting comparison groups on the basis of the estimated standard errors of the conditional mean of wealth given the explanatory variables from the two equations. The basic idea is that persons with low standard errors have characteristics that are closer to the center of the multivariate distribution of the control variables. We use the estimate of the variance matrix of the black coefficient estimates to calculate prediction errors for each white sample member and then pick the ones that have the lowest estimated prediction error. Blacks are treated analogously. There is a tradeoff between reduction in sample size for the comparisons and the objective of focusing on whites who fall within the distribution of characteristics of blacks, and vice versa. Somewhat arbitrarily, we chose $50 \%$ as the percentage of the white and the black samples to keep for the wealth decompositions. (The model estimates are based on the full samples.) The results for wealth levels and wealth/permanent income ratios are presented in Table 5.

Comparing the $50 \%$ of blacks with the lowest prediction error based upon the white wealth model with the $50 \%$ of whites with the lowest prediction error based upon the black wealth model, the estimated gap in $W$ for couples 
is $50,121(3,054)$. Note that the gap between these groups is about $43 \%$ of the gap for the full samples because the whites we have chosen have characteristics that tend to fall within the distribution for blacks, and vice versa. For this reason, we examine the size of the unexplained gap relative to the mean of wealth of whites as well as the percentage of the gap explained.

The unexplained gap based on the white wealth model is only $14 \%$ of the wealth of whites in the subsample, while the corresponding unexplained gap based on the black wealth model is $39 \%$ of white wealth. For single females the corresponding numbers are $9 \%$ and $57 \%$, and for black males the numbers are $-32 \%$ and $55 \%$. The explained gap using the white wealth model is 36,814 , which is $73 \%$ of the total gap for the subsample. Using the black coefficients the explained gap is only $27 \%$ of the total. For single females the corresponding percentages are $87 \%$ and $22 \%$. For single black males the corresponding percentages are $151 \%$ and $11 \%$. The results for $W / y$ follow a similar pattern, but the difference in the percentage of the gap explained using the white and black wealth models is smaller.

Overall, our use of prediction errors to identify a subsample of white and blacks who are closer in terms of the observables that matter for wealth confirms our basic finding that differences in the white and black wealth models play a key role in the wealth gap.

As a final robustness check we start with the trimmed sample and prior to estimation of the wealth models eliminate observations if current income is negative and/or if permanent income is less than 100, and eliminate observations for whites with permanent income values (current income values) above the maximum value for permanent income (current income) in the black sample. In the case of couples, we screen on the basis of both the husband's permanent income and the wife's permanent income. The results are very similar to those in Table 3 and are available upon request.

Based on the robustness checks performed, we conclude that the discrepancy between the white and black wealth models in the importance of 
income and demographic variables is real rather than an artifact caused by inaccurate extrapolation out of sample.

\section{Results for Components of Wealth}

Why are the coefficients so different across the black and white specifications? One hypothesis is that the relationship differs for some forms of wealth but not for others. Table 6 reports mean regression decompositions along with OLS standard errors of main home equity (house value net of mortgage balance), stocks/mutual funds and IRAs, and wealth in farms/businesses for the sample of couples. The regressors are the same as the ones used for couples in the other models.

On average whites hold 32,309 (978) more home equity than blacks $(56,859$ (657) versus 24,550 (724), Table 6, Panel A), which is not surprising given the difference in home ownership rates across races. ${ }^{20}$ The white regression model explains $88 \%$ of this gap compared to the $79 \%$ explained for the combined wealth assets in Table 3. Again, the amount explained using the model for blacks is much smaller - only $30 \%$.

The unconditional black/white difference in asset holdings relative to the mean for either group is significantly larger for stocks and business wealth. In the case of stocks, the mean for whites and blacks are 23,290 (915) and 2,670 (314) respectively. The total gap of $20,620(1,558)$, is 7.7 times the mean for blacks. We can attribute $88 \%$ of the difference in stock to income and demographic characteristics when we use the wealth model for whites but only $20 \%$ of the difference when we use the black wealth model. The gap in this component is particularly important given the equity premium. Even

\footnotetext{
${ }^{20}$ Charles \& Hurst (2001) provide evidence that differences between blacks and whites in the ability and willingness of parents to provide a downpayment plays a role in the lower transition rate from rental status to home ownership for blacks. Segal \& Sullivan (1998) study the role of race, other demographic variables, and income in trends in home ownership.
} 
if blacks and whites received the same return on any given asset, the fact that equity is underrepresented in the portfolios of black couples suggests that overall returns are lower for blacks.

The wealth model for whites explains only $73 \%$ of the gap in farm/business wealth even though self-employment status of the husband and wife are controlled. Once again, the fractions explained by the black regression equation are negligible - only $18 \%$. We obtain qualitatively similar results for the ratios of the various wealth components to permanent income of the head, although the explanatory power of both the white wealth model and the black wealth model is lower for $W / y$ (Table 6, Panel B).

Overall, the results for the components of wealth closely parallel the results for total wealth.

\section{Intergenerational Transfers and the Wealth Gap: Evidence for Siblings}

\subsection{Motivation}

Our results show substantial differences in the sensitivity of wealth holding to income and demographic variables. Because both income and demographic characteristics of whites are more conducive to wealth holding, we assign higher fractions of the wealth gap to differences in income and demographics when we use the white wealth equations. There are at least three possible explanations for why wealth holding may be more sensitive to characteristics for whites than for blacks. First, whites may enjoy a higher rate of return on assets, in which case the same level of savings and intergenerational transfers would lead to larger wealth levels, magnifying underlying differences that are associated with income and demographics. Menchik \& Jianakoplos (1997) provide some limited evidence that blacks experience a lower rate of return on assets of a given type. However, the evidence on this point is far from conclusive. Second, savings of blacks may be less sensitive 
to the income and demographic variables that we use. Third, inheritances of housing, financial assets and businesses and/or inter vivos transfers are larger among whites than among blacks because slavery and the legacy of racial discrimination have inhibited the accumulation of wealth in the black

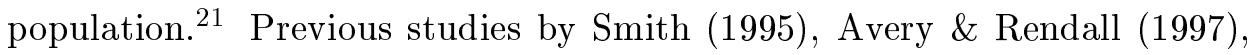
and Menchik \& Jianakoplos (1997) indeed suggest that differences in inheritances explain part of the race gap, although neither study pays much attention to the fact that there are large discrepancies between whites and blacks in the sensitivity of wealth holding to income and demographics. ${ }^{22}$

In this section we use data on siblings to explore the possibility that differences in intergenerational transfers are the source of differences in wealth holding. Using siblings largely neutralizes the effects of differences between whites and blacks in inter vivos transfers and inheritances and provides a way of controlling for the effects of adverse history on the position of blacks relative to whites with similar income and demographics. ${ }^{23}$

Let $k$ index families and $i$ siblings within a family. We estimate models of the form

$$
W_{k i t}^{j}=\alpha_{0}^{j}+Y_{k i t}^{j} \alpha^{j}+X_{k i t}^{j} \beta^{j}+u_{k}^{j}+\epsilon_{k i t}^{j}, \quad j=b, w,
$$

\footnotetext{
${ }^{21}$ Indeed, this "sedimentation of racial inequality" is one of three major themes put forth in Oliver \& Shapiro (1997) sociological analysis of the wealth gap, who provide a historical overview of legal and social barriers to wealth holding by blacks.

${ }^{22} \mathrm{~A}$ fourth possibility is that blacks face higher prices than whites. In this case, our measure of real income is overstated for blacks. However, the available evidence suggests that consumer prices are not very different for blacks than for whites (Richburg Hayes 2000).

${ }^{23}$ The coefficients in the sibling equations will be downward biased to the extent that parents try to compensate for differences in income of children. However, Menchik (1980), Wilhelm (1996), Menchik \& David (1983) and other studies show that inheritances are evenly split in about $70 \%$ of the cases and that the division is only weakly related to income in the cases where the split is not even. Inter vivos transfers among siblings tend to compensate for income differences, but the coefficient relating transfer amounts to income differences is relatively small. See Altonji, Hayashi \& Kotlikoff (1997) and McGarry \& Schoeni (1995) for evidence.
} 
where $u_{k}^{j}$ is a family-specific fixed effect. For reasons that will become clear later, we have made the wealth survey year subscript $t$ explicit. If inheritances and inter vivos transfers are correlated with average income and demographic characteristics of the siblings, then $u_{k}^{j}$ will be correlated with $Y_{k i t}^{j}$ and $X_{k i t}^{j}$. Since inheritances and transfers are larger for whites than blacks, the resulting bias may be larger for whites. By controlling for factors that are common to siblings, we reduce this problem.

To see how historical barriers to wealth holding faced by blacks affect the estimated slopes of wealth models and how fixed effects models reduce the influence of these barriers, consider the following simple model of inheritances and inter vivos transfers. Suppose that in a steady state the wealth of parents, including inheritances and accumulated savings, is related to permanent income $y$ according to

$$
W_{0}=\alpha y_{0},
$$

where we have suppressed family and survey year subscripts and use the subscript 0 to denote the parents. Suppose also that parents pass on the fraction $\phi$ of their wealth. Furthermore, assume that the relationship between the permanent incomes of parents and children is

$$
y_{0}=\rho y_{1}, \quad \rho>0
$$

where the subscript 1 denotes the child. For whites, the child's wealth is the sum of savings out of gifts and inheritances and savings out of income,

$$
W_{1}=s\left(\phi W_{0}+g y_{1}\right)=(s \alpha \phi \rho+s g) y_{1},
$$

where $g$ converts permanent income into the discounted sum of lifetime income and $s$ is the savings rate. Suppose that slavery and discrimination severely limited the ability of blacks to accumulate wealth. Then the relationship between wealth and permanent income of the black parents can be modeled

$$
W_{0}=d\left(\alpha y_{0}\right), \quad 0<d<1,
$$


where $d$ reflects the effect of discrimination. Hence, the equation relating wealth to income for blacks is

$$
W_{1}=s\left(\phi W_{0}+g y_{1}\right)=(s \alpha \phi d \rho+s g) y_{1}
$$

The coefficent $(s \alpha \phi d \rho+s g)$ on $y_{1}$ in the above equation for blacks is smaller than the coefficient $(s \alpha \phi \rho+s g)$ for whites. However, once the effect of parental wealth is held constant using a family-specific fixed effect, the influence of the term $s \phi W_{0}$ is eliminated and the coefficient on $y_{1}$ is $s g$ for both whites and blacks. A similar argument can be made for intergenerational links in demographic patterns. Hence, if the analyses with and without fixed effects give similar answers, then we can conclude that race differences in gifts and inheritances that are correlated with income and demographic variables do not explain our finding that wealth levels are more sensitive to income and demographic variables in the case of whites than in the case of blacks. $^{24}$

\subsection{Results for Siblings}

To obtain adequate sample sizes, we pool observations on single men, single women, and couples and add control variables for the three demographic groups. For couples we use only the head's variables rather than separate variables for the husband and the wife. As before, we pool wealth observations across the 1984, 1989, and 1994 wealth supplements. We do not weight

\footnotetext{
${ }^{24}$ An alternative strategy is to add controls for the permanent income and wealth of parents. Conley (1999) controls for such variables in a model for the log of wealth and finds that he can explain the entire wealth gap. However, his analysis is likely to overestimate the effects of parental income and wealth because he excludes permanent income measures for the adult children and ignores the effects of unobserved family specific heterogeneity in savings behavior. Furthermore his sample size is very small and contains similar percentages of whites and blacks who are self employed (in contrast to a huge literature and the evidence in Table 1). Also, he works with a pooled regression model and reports standard errors that are so large that the results are not very informative. Further research incorporating parental wealth is needed.
} 
observations in computing the decompositions.

When one includes a family fixed effect, the effects of permanent income are identified only by cross-sibling variation, but the effects of current income, self-employment status, marital status, the number of children, and other explanatory variables that change over time are identified by a mix of cross-sibling variation and cross-time variation. OLS without fixed effects uses cross-family, cross-sibling, and cross-time variation. One might argue that cross-person variation should have a stronger relationship with wealth than cross-time variation. Moreover, for the purpose of explaining the race gap in wealth the effects of permanent differences are more important than transitory differences. For this reason, we also examine estimates that emphasize cross-sibling variation. A simple way to use only cross-sibling variation in the key income and demographic variables is to estimate the wealth model after taking person means across wealth surveys for all of the variables. However, with time averaging it becomes difficult to distinguish the effects of current and permanent income, and much variation in variables such as the survey year dummies and age is lost.

To save space, we do not report the detailed regression estimates. However, it is interesting to note that although the race gap in the effect of income on wealth is a little smaller for FE than OLS it is somewhat larger for FE-Means than OLS. ${ }^{25}$ Overall, there is not much evidence that race differences in the correlation between income and inheritances plays a large role in the stronger relationship between income and wealth for whites.

There is an interesting pattern in coefficients on self employment. The OLS and FE estimates of the effect of self employment are 70,013 and 49,116

\footnotetext{
${ }^{25}$ The fixed effect estimate of the marginal effect of a one dollar increase in both current income and permanent income is $1.49,2.26$, and 2.82 when both are set to $0.5,1.0$, and 1.5 times their respective means for the pooled sibling sample. The corresponding fixed effects estimates for blacks are 0.78, 1.62 and 2.46. The corresponding FE-Means estimates are 1.30, 2.02 and 2.73 for whites and $.98, .99$ and .99 for blacks. The corresponding OLS estimates are 1.77, 2.32 and 2.88 using the white model and $.89,1.52$ and 2.15 using the black model.
} 
for whites. The OLS-Means and FE-Means estimates are 85,232 and 60,751. Both reporting error and the fact that successful businesses are longer lasting may underlie the fact that the estimates are larger when we work with individual means. The fact that the estimates decline when sibling fixed effects are included is consistent with a role for inheritances in the effects of self employment but it may also be due to a greater role for reporting error. The OLS and FE estimates for blacks are 14,230 and 11,854 and the OLS-Means and FE-Means estimates are 12,116 and 9,804. Thus, adding family fixed effects closes the race gap in the link between self employment and wealth from 73,116 to 50,948 when individual means are taken and from 55,783 to 37,262 when means are not taken. For $W / y$ the gap is 1.03 for OLS and .594 for FE. The gap is 1.47 for OLS-Means and .942 for FE-Means. Overall, the self-employment results for siblings confirm our earlier results suggesting that self employment may play a substantial role in the wealth gap. The comparison of the estimates with and without fixed effects suggests that parental wealth or other family background factors can explain about one third of the huge race gap in the relationship between self employment and wealth. ${ }^{26}$

In Table 7 we report decompositions of the wealth gap using the siblings sample using FE and FE-Means estimates of the wealth models. For purposes of comparison, we also report OLS and OLS-Means estimates. In performing the decompositions we use the means for whites and for blacks based on the full sibling sample regardless of the estimation method used. We do not use population weights in these decompositions.

The results are quite striking. For the wealth level we explain $111 \%$ and $54 \%$ of the gap using the white coefficients and the black coefficients, respectively, using OLS, $104 \%$ and $49 \%$ using FE, $107 \%$ and $36 \%$ using

\footnotetext{
${ }^{26}$ Fairlie \& Meyer (2000) consider estimates of intergenerational links in self employment and conclude that most of the racial discrepancy in self-employment rates is due to "forces that reduce current black self employment besides the initial conditions of low black self employment."
} 
OLS-Means, and $97 \%$ and $23 \%$ using FE-Means. Basically, the FE and FEMeans results closely correspond to the results without fixed effects, and mirror the pattern we obtained above for the samples of couples, single females, and single males. We continue to explain more of the wealth gap using the white coefficients than the black coefficients, particularly when wealth and income are specified in levels. The $W / y$ results are very similar to the $W$ results. ${ }^{27}$ If anything, the gap in the fraction of wealth explained using the black wealth model and the white wealth model is larger when we use cross-sibling variation to eliminate the effects of common inheritances and transfers. There is little evidence that differences in factors such as inheritances or inter vivos transfers that are likely to vary across families provide an explanation for the racial difference in the sensitivity of wealth to income and demographics. They may, however, play a role in differences in wealth intercepts and appear to matter for self employment. This leaves differences in savings behavior and/or rates of return as potential sources of the race difference in wealth models. We turn to examining them in the next section.

There is an important caveat to our analysis. The additively separable form of equation (4) is standard in the literature, but the fact that wealth is a convex function of income suggests that inheritances may interact positively with income if a bequest motive is an important reason for individuals to accumulate wealth. In this circumstance, an additively separable fixed effect may not be an adequate control for unobserved heterogeneity due to inheritances and other factors, particularly in a wealth level equation. The results for the wealth/permanent income ratio are less subject to this objection, but it is important to keep in mind that the explanatory power of the white and black wealth models is smaller for ratios than for levels. ${ }^{28}$

\footnotetext{
${ }^{27}$ The fixed effects results for $\ln W$ are also similar to our earlier results in Table 3 .

${ }^{28}$ Altonji \& Matzkin (2001) provide a panel data estimator for nonseparable models could be used to address the issue, which we leave to future research.
} 


\section{Race Differences in the Growth of Wealth}

We now turn to models of wealth accumulation. In Table 8 we present unweighted means and standard deviations of the measures of the 5 year changes in wealth for couples. The 5 year changes reflect the growth in wealth between the 1984 and 1989 surveys or between the 1989 and 1994 surveys. The first two columns are based on the full sample and include outliers. The next two columns as well as the regression decompositions below are based upon a trimmed sample.

We focus on the trimmed statistics. These show a much more rapid rate of accumulation for whites than for blocks. For example, the mean 5 year change in $W / y$ is 1.28 (3.71) for whites but only 0.45 (2.11) for blacks, a gap of 0.83 . The large difference could reflect differences in savings, differences in rates of return on assets, or a combination of the two. Table 8 also reports the mean growth rates for some categories of wealth. There are dramatic differences between whites and blacks in growth of housing wealth and especially in stock/mutual funds/IRAs and in business wealth.

We now turn to the issue of how much of the difference in accumulation rates can be explained by differences and income and demographic characteristics. The growth models include the variables that appear in the wealth models plus the changes in the measures of current income, children, dependents, health status, self employment, region, and SMSA. To insure reasonable sample sizes we confine the analysis to couples. We focus on total wealth because the precision for the components is not sufficiently large. We do not weight observations in computing the decompositions.

The wealth change decompositions are reported in Table 9 . In the case of $W$, income and demographic variables explain $74 \%$ of the difference in accumulation rates when the accumulation model for whites is used. Using the accumulation model for blacks, the same factors explain $49 \%$ of the gap. The corresponding figures for growth in the wealth/permanent income ratio, $W / y$, is $84 \%$ based on the white accumulation model and $30 \%$ based on 
the black accumulation model. In summary, we find that income and demographic characteristics explained more of the gap in wealth accumulation when the wealth model for whites is used.

What is responsible for the substantial difference between blacks and whites in the sensitivity of wealth levels and wealth/permanent income ratios to income and demographic variables? Difference in the rate of return to wealth may be part of the story, because blacks have larger percentages of their wealth in home equity and smaller percentages in stocks and business wealth. However, the differences seem too great to be attributable to differences in rate of return alone although further research on this issue is needed. The wealth change regressions suggest that differences in savings rates are an important factor. Recall that our sibling results show that inheritances and gifts are not a major factor in the black/white differences in the wealth models. This fact, in combination with the substantial race differences in the wealth growth models, suggests that differences in savings behavior (possibly in combination with rates of return) may be an important source of the wealth gap and of white/black differences in the wealth model parameters. ${ }^{29}$

\footnotetext{
${ }^{29}$ We have also estimated equations for $W$ that include a lagged value of $W$ along with the other variables used in the savings regressions. We estimated corresponding models for $W / y$ and $\ln W$. The models do not have a structural interpretation but should say something about race differences in accumulation behavior if they exist. When we use OLS to estimate the models, we obtain a coefficient on lagged wealth of .817 with a standard error of (.017) for whites and .596 (.045) for blacks. (Hurst et al. (1998) analyze wealth dynamics using contingency tables and find that wealth is more transitory for blacks, which is in line with our estimates.) We explain $99 \%$ of the gap in wealth in 1994 with income demographics and lagged wealth when we use the white equation and $67 \%$ when we use the equation for blacks. The coefficient on lagged wealth is likely to be biased upward by persistent differences across households in factors that influence wealth and biased downward by reporting error. To deal with the latter problem we have also estimated the models using the second lag of wealth as an instrument for the lag first of wealth. The coefficient on the lag of wealth is $1.36(.200)$ for whites and .881 (.129) for blacks. We can explain $97 \%$ of the gap in wealth in 1994 with income, demographics and
} 
Note that the results for logs in Panel $\mathrm{C}$ of Table 9 present a challenge to the above interpretation. The results for logs show that $77 \%$ of the wealth is explained when the black wealth growth model is used while only $5 \%$ of the gap is explained when the white $\log$ wealth growth model is used. These results are not consistent with the results in Panels A and $\mathrm{B}$ and cannot be attributed to the fact that the log model is basically a multiplicative specification. We do not have a good explanation for this, but note that many of the coefficients in the model are poorly estimated and the explanatory power of both the white model and black model is low. In general, the low explanatory power of the growth models makes us cautious in interpreting the decompositions, especially in the case of the models for blacks. ${ }^{30}$

\section{Conclusions and Further Questions}

We study the sources of the huge wealth disparity between blacks and whites using improved income and demographic measures. When we use the level of wealth as the dependent variable we can explain a large part of the huge racial disparity in wealth holdings with income and demographic variables provided that we estimate the wealth model on a sample of whites. In the case of couples these factors account for between $79 \%$ and $95 \%$ of the wealth gap depending on how we construct permanent income. For single males and

lagged wealth using the equation for whites and $83 \%$ using the equation for blacks. In the case of the $W / y$ the OLS (2SLS) estimate of the coefficient on the lag of $W / y$ is .9677 (1.027) for whites and .6357 (1.39) for blacks, but the standard errors are large in the 2SLS case. Both 2SLS models explain $100 \%$ of the gap. However, given the presence of lagged wealth, the high explanatory power of the models is largely due to the race gap in lagged wealth, and so it is hard to know what the economic significance of the explained gap is.

${ }^{30}$ The adjusted $R^{2}$ 's of the growth models are only about .05 for the growth in $\ln W$. The adjusted $R^{2}$ is .0946 for whites and .0458 for blacks when the dependent variable is the growth in $W / y$ and .3023 for whites but only .0607 for blacks when the dependent variable is the growth in $W$. 
single females income and demographic factors account for the entire gap.

On the other hand, we can explain only a small fraction of the race gap when we ask the question: If the relationship between wealth and income and demographics for whites was the same as it is for blacks, how much wealth would whites hold? In general, the regression coefficients relating income and demographic characteristics to wealth are much smaller for blacks. The smaller coefficients mean that less of the race gap in wealth is explained by the gap in income and demographics. In the case of main home equity, stocks/mutual funds and IRAs, and wealth in farms/businesses we also find that income and demographic differences explain much more of the gap when one uses the white model than when one uses the black model. We find that a higher self-employment rate and a stronger link between self employment and wealth for whites both make an important contribution to the wealth gap between white and black couples, although the direction of causality between the self-employment rates and wealth is ambiguous.

Our results are robust to a number of modifications to the estimation methodology, functional form, and comparison groups, although the skewed nature of the wealth distribution and the lack of overlap between blacks and whites at the high end of the income distribution makes the seemingly straightforward task of decomposing the wealth gap difficult. Overall, the results suggest that the role in the wealth gap of race differences in the sensitivity of wealth to income and demographics may be as important as the race gap in income and demographics themselves.

What underlies the substantial race differences in the sensitivity of wealth holding to income and demographics? To answer this question we analyse data on siblings from the PSID. The fact that we obtain similar results when we relate sibling differences in wealth to sibling differences in income and demographics suggests, perhaps surprisingly, that differences in inter vivos transfers and inheritances are not the main reason the wealth model coefficients differ by race. This would seem to leave race differences in sav- 
ings behavior and/or rates of return as a default explanation. We find that income and demographic differences explain a substantial part of the difference between whites and blacks in the growth in the level of wealth and in the ratio of wealth to permanent income when we use the wealth model for whites, but relatively little when we use the wealth model for blacks. This result suggests important differences between whites and blacks in the effects of income and demographics on savings or rates of return, although our conclusion is tentative for a number of reasons discussed above. We suspect that differences in savings behavior is the main factor. However, the fact that blacks hold disproportionately low fractions of their portfolios in stocks and business wealth suggests that differences in rates of return may also play a role.

A large research agenda remains. Further descriptive explorations of the gap in the level and growth of wealth using other data sets and other econometric approaches are needed. However, more detailed studies of the underlying causes of race differences in wealth accumulation behavior are also needed. We close by sketching a few possibilities. Our sibling approach to the the study of the effects of parental resources on the wealth models should be augmented by a careful study of intergenerational links in wealth holding. The role of self employment and small business formation has already received a substantial amount of attention in the literature and deserves more. A second possibility is that differences in permanent income in conjunction with lower life expectancies among blacks and a higher replacement rate of private income with publicly provided social security and health benefits depress the incentive to save for retirement of blacks relative to whites, as discussed by Smith (1995). ${ }^{31}$ Differences in life expectancy may also play a role, although we suspect it to be minor.

\footnotetext{
${ }^{31}$ In preliminary work using the Health and Retirement Survey (HRS), John Karl Scholz (University of Wisconsin, Madison) has found that the race gap is much smaller for pensions than other forms of wealth (personal communication). This could have spillovers into holding of assets.
} 
A third possibility revolves around the implications of differences in the income distributions of the friends and relatives of whites versus blacks. The basic idea is that savings and wealth accumulation are influenced by economic links to other household and friends that are motivated by altruism or other factors. The effects of ties to other households on savings depends on the level and distribution of resources and needs. We know that wealth accumulation is highly nonlinear in income. An explanation for this is that the marginal utility of household consumption declines in spending, leading households to accumulate resources as a hedge against future consumption needs, fluctuations in income, and uncertainty about the lifespan. Unspent resources are left to children or to charity late in life or upon death. However, if a high income family has strong ties to needy relatives and friends, it may make transfers rather than accumulate wealth. Also, social pressure on the relatively well off to provide assistance may be stronger in communities where needs are greatest. This will reduce the private incentive to accumulate for those who are not very altruistic. The net result may be that the wealth of a household with an extensive network of needy family members and friends may increase less with income than the wealth of a household with a network of well off friends and relatives.

Finally, the lower incomes of black households and of their friends and relatives may lead to greater dependence on social transfer programs relative to own resources and private transfers, holding permanent income and other household characteristics constant. Eligibility requirements for many transfer programs, including welfare programs and public housing, discourage wealth accumulation. This may reduce the private incentive to accumulate wealth. ${ }^{32}$

\footnotetext{
${ }^{32}$ This possibility is analyzed by Hubbard, Skinner \& Zeldes (1995). Their simulation methodology could be adapted to address the other possibilities mentioned above. See Powers (1998), Gruber \& Yelowitz (1999), and Hurst \& Ziliak (2001) for direct evidence on the effects of asset limits on savings.
} 


\section{References}

Altonji, J., Doraszelski, U. \& Segal, L. (2000). Black/white differences in wealth, Economic Perspectives 24(1): 38-50.

Altonji, J., Hayashi, F. \& Kotlikoff, L. (1997). Parental altruism and inter vivos transfers: Theory and evidence, Journal of Political Economy 105(6): 1121-1166.

Altonji, J. \& Matzkin, R. (2001). Panel data estimators for nonseparable models with endogenous regressors, Working paper, Northwestern University, Evanston.

Altonji, J. \& Villanueva, E. (2001). The effect of parental income on wealth and intended bequests, Working paper, Northwestern University, Evanston.

Avery, R. \& Rendall, M. (1997). The contribution of inheritances to blackwhite wealth disparities in the United States, Working paper, Board of Governors of the Federal Reserve System.

Blau, F. \& Graham, J. (1990). Black-white differences in wealth and asset composition, Quarterly Journal of Economics 105(2): 321-339.

Blinder, A. (1973). Wage discrimination: Reduced form and structured estimates, Journal of Human Resources 8: 436-455.

Charles, K. \& Hurst, E. (2001). The transition to home ownership and the black-white wealth gap, Review of Economics and Statistics forthcomming.

Conley, D. (1999). Being black, living in the red: Race, wealth, and social policy in America, University of California Press, Los Angeles. 
DiNardo, J., Fortin, N. \& Lemieux, T. (1996). Labor market institutions and the distribution of wages, 1973-1992: A semiparametric approach, Econometrica 64(5): 1001-1044.

Fairlie, R. \& Meyer, B. (1997). Ethnic and racial self-employment differences and possible explanations, Journal of Human Resources 31(4): 757-793.

Fairlie, R. \& Meyer, B. (2000). Trends in self-employment among white and black men during the twentieth century, Journal of Human Resources 35(4): 543-669.

Gruber, J. \& Yelowitz, A. (1999). Public health insurance and private savings, Journal of Political Economy 103(2): 1249-1274.

Hubbard, G., Skinner, J. \& Zeldes, S. (1995). Precautionary savings and social insurance, Journal of Political Economy 103(2): 360-399.

Hurst, E., Luoh, M. \& Stafford, F. (1998). The wealth dynamics of American families, 1984-94, Brookings Papers on Economic Activity 1: 267-329.

Hurst, E. \& Ziliak, J. (2001). Welfare reform and household saving, Working paper, University of Oregon, Seattle.

Koenker, R. \& Bassett, G. (1978). Regression quantiles, Econometrica 46(1): $33-50$.

McGarry, K. \& Schoeni, R. (1995). Transfer behavior in the Health and Retirement Study: Measurement and the redistribution of resources within the family, Journal of Human Resources 30(Supplement): S184S226.

Menchik, P. (1980). Primogeniture, equal sharing, and the U.S. distribution of wealth, Quarterly Journal of Economics 94(2): 299-316.

Menchik, P. \& David, M. (1983). Income distribution, lifetime savings, and bequests, American Economic Review 73(4): 672-690. 
Menchik, P. \& Jianakoplos, N. (1997). Black-white wealth inequaility: Is inheritance the reason?, Economic Inquiry 35: 428-442.

Narula, S. \& Wellington, J. (1982). The minimum sum of absolute errors regression: A state of the art survey, International Statistical Review 50: $317-326$.

Oaxaca, R. (1973). Male-female wage differentials in urban labor markets, International Economic Review 14(2): 693-709.

Oliver, M. \& Shapiro, T. (1997). Black wealth / white wealth, Routledge, London.

Powers, E. (1998). Does means-testing welfare discourage savings? evidence from a change in AFDC policy in the United States, Journal of Public Economics 68(1): 33-53.

Richburg Hayes, L. (2000). Do the poor pay more? An empirical investigation of price dispersion in food retailing, Working paper, Rutgers University, New Brunswick.

Segal, L. \& Sullivan, D. (1998). Trends in home ownership: Race, demographics and income, Economic Perspectives 22(2): 53-72.

Smith, J. (1995). Racial and ethnic differences in wealth in the Health and Retirement Study, Journal of Human Resources 30(Supplement): S158-S183.

Wilhelm, M. (1996). Bequest behavior and the effect of heirs' earnings: testing the altruistic model of bequests, American Economic Review 86(4): $874-892$. 
Table 1: Descriptive statistics for wealth and income variables

\begin{tabular}{|c|c|c|c|c|c|c|}
\hline & $\begin{array}{l}\text { White } \\
\text { Couples } \\
\text { (std. dev.) }\end{array}$ & $\begin{array}{l}\begin{array}{l}\text { Black } \\
\text { Couples } \\
\text { (std. dev.) }\end{array} \\
\end{array}$ & $\begin{array}{c}\text { Single White } \\
\text { Males } \\
\text { (std. dev.) }\end{array}$ & $\begin{array}{c}\text { Single Black } \\
\text { Males } \\
\text { (std. dev.) }\end{array}$ & $\begin{array}{l}\text { Single White } \\
\text { Females } \\
\text { (std. dev.) }\end{array}$ & $\begin{array}{c}\text { Single } \\
\text { Black } \\
\text { Females } \\
\text { (std. dev.) }\end{array}$ \\
\hline \multirow[t]{2}{*}{ Log of wealth including main home equity } & 10.97 & 9.48 & 8.95 & 7.25 & 9.19 & 6.88 \\
\hline & (2.11) & (2.35) & (2.76) & (2.82) & $(2.80)$ & (2.88) \\
\hline Wealth including main home equity & $\begin{array}{r}211602 \\
(627938)\end{array}$ & $\begin{array}{r}53472 \\
(140253)\end{array}$ & $\begin{array}{r}62211 \\
(153775)\end{array}$ & $\begin{array}{r}15439 \\
(38141)\end{array}$ & $\begin{array}{r}70599 \\
(208029)\end{array}$ & $\begin{array}{r}15099 \\
(40543)\end{array}$ \\
\hline \multirow[t]{2}{*}{ Ratio of wealth including main home equity to permanent income } & 4.87 & 1.80 & 1.33 & 0.58 & 2.04 & 0.66 \\
\hline & $(11.26)$ & $(4.36)$ & (3.12) & $(1.68)$ & $(7.50)$ & $(1.88)$ \\
\hline \multirow[t]{2}{*}{ Value home } & 70082 & 38129 & 50050 & 29543 & 57438 & 30737 \\
\hline & (78227) & (60736) & (58305) & (22066) & (158915) & (39325) \\
\hline \multirow[t]{2}{*}{ Value farm/business } & 191367 & 60075 & 70205 & 46366 & 80793 & 25758 \\
\hline & (548572) & (198798) & (128588) & (160601) & (114727) & (31834) \\
\hline \multirow[t]{2}{*}{ Value stock/mf/ira } & 68914 & 26837 & 33783 & 8623 & 38816 & 8851 \\
\hline & (293569) & (51006) & (120410) & (11312) & (76743) & (14906) \\
\hline \multirow[t]{2}{*}{ Value home (incl. 0) } & 58462 & 25293 & 18335 & 6475 & 27534 & 9157 \\
\hline & $(76053)$ & $(52647)$ & $(42741)$ & $(16002)$ & $(113707)$ & (25658) \\
\hline \multirow[t]{2}{*}{ Value farm/business (incl. 0) } & 39149 & 2689 & 8195 & 990 & 4375 & 103 \\
\hline & (259850) & (43853) & (49379) & (24411) & (32359) & (2592) \\
\hline \multirow{2}{*}{ Value stock/mf/ira (incl. 0) } & 27589 & 4073 & 8619 & 581 & 9138 & 519 \\
\hline & (188793) & (22080) & (62578) & (3646) & (40715) & (4164) \\
\hline \multirow{2}{*}{ Ratio of value of home to permanent income } & 1.78 & 1.38 & 1.12 & 1.13 & 1.70 & 1.43 \\
\hline & $(1.83)$ & (1.63) & (1.33) & $(0.90)$ & $(8.11)$ & (2.11) \\
\hline \multirow[t]{2}{*}{ Ratio of value of farm/business to permanent income } & 3.95 & 1.63 & 1.64 & 2.00 & 2.57 & 1.23 \\
\hline & (10.01) & (3.47) & (3.26) & (7.84) & (3.89) & $(1.81)$ \\
\hline \multirow[t]{2}{*}{ Ratio of value stock/mf/ira to permanent income } & 1.37 & 0.69 & 0.61 & 0.28 & 1.08 & 0.32 \\
\hline & $(3.30)$ & $(1.23)$ & $(1.53)$ & $(0.39)$ & $(2.23)$ & $(0.61)$ \\
\hline \multirow[t]{2}{*}{ Ratio of value home (incl. 0) to permanent income } & 1.48 & 0.92 & 0.41 & 0.25 & 0.82 & 0.43 \\
\hline & $(1.80)$ & (1.48) & $(0.97)$ & $(0.63)$ & (5.68) & (1.33) \\
\hline \multirow[t]{2}{*}{ Ratio of value farm/business (incl. 0 ) to permanent income } & 0.81 & 0.07 & 0.19 & 0.04 & 0.14 & 0.00 \\
\hline & $(4.80)$ & $(0.81)$ & $(1.23)$ & $(1.18)$ & $(1.08)$ & $(0.14)$ \\
\hline \multirow[t]{2}{*}{ Ratio of value of stock/mf/ira (incl. 0 ) to permanent income } & 0.55 & 0.10 & 0.16 & 0.02 & 0.26 & 0.02 \\
\hline & $(2.20)$ & $(0.54)$ & $(0.82)$ & $(0.12)$ & (1.18) & $(0.17)$ \\
\hline Whether home & 0.83 & 0.66 & 0.37 & 0.22 & 0.48 & 0.30 \\
\hline Whether farm/business & 0.20 & 0.04 & 0.12 & 0.02 & 0.05 & 0.00 \\
\hline Whether stock/mf/ira & 0.40 & 0.15 & 0.26 & 0.07 & 0.24 & 0.06 \\
\hline \multirow[t]{2}{*}{ Log of taxable non-asset income } & 10.35 & 10.06 & 9.68 & 9.12 & 9.27 & 8.92 \\
\hline & $(0.80)$ & $(0.78)$ & $(0.90)$ & $(1.07)$ & $(0.88)$ & $(0.90)$ \\
\hline \multirow[t]{2}{*}{ Permanent log-income } & 10.72 & 10.32 & 10.56 & 9.91 & 10.52 & 9.94 \\
\hline & $(0.49)$ & $(0.54)$ & $(0.57)$ & $(0.72)$ & $(0.56)$ & $(0.63)$ \\
\hline \multirow[t]{2}{*}{ Total taxable non-asset income } & 41519 & 30153 & 22452 & 14204 & 14618 & 10590 \\
\hline & (43788) & (19985) & (19181) & (11887) & (26781) & (8844) \\
\hline \multirow[t]{2}{*}{ Permanent income } & 46949 & 32450 & 45317 & 28413 & 38939 & 25045 \\
\hline & (20613) & (12747) & (17643) & (9683) & (13731) & (7872) \\
\hline \multirow[t]{2}{*}{ Spouse: Permanent log-income } & 10.66 & 10.25 & & & & \\
\hline & $(13097)$ & $(30086)$ & & & & \\
\hline Spouse: Permanent income & $(22636)$ & $(13681)$ & & & & \\
\hline Number of observations & 7700 & 2509 & 1415 & 1130 & 2744 & 3178 \\
\hline from 1984 wealth survey & 2561 & 910 & 442 & 335 & 898 & 1036 \\
\hline from 1989 wealth survey & 2777 & 931 & 502 & 426 & 912 & 1090 \\
\hline from 1994 wealth survey & 2362 & 668 & 471 & 369 & 934 & 1052 \\
\hline Number of couples/singles & 3444 & 1280 & 924 & 701 & 1562 & 1587 \\
\hline
\end{tabular}

Notes: Computed from the pooled sample using weights. The weights are normalized so that for each subgroup the means are estimates of the average of the population means for 1984, 1989, and 1994. "Value of stock/mf/ira" refers to the value of shares of stock in publicly held corporations, mutual funds or investment funds, including stocks in IRAs. The definition of permanent income is given in the text. 
Table 2: Descriptive statistics for demographic variables

\begin{tabular}{|c|c|c|c|c|c|c|}
\hline & $\begin{array}{l}\text { White } \\
\text { Couples } \\
\text { (std. dev.) }\end{array}$ & $\begin{array}{c}\text { Black } \\
\text { Couples } \\
\text { (std. dev.) }\end{array}$ & $\begin{array}{c}\text { Single } \\
\text { White } \\
\text { Males } \\
\text { (std. dev.) }\end{array}$ & $\begin{array}{c}\text { Single } \\
\text { Black } \\
\text { Males } \\
\text { (std. dev.) }\end{array}$ & $\begin{array}{c}\text { Single } \\
\text { White } \\
\text { Females } \\
\text { (std. dev.) }\end{array}$ & $\begin{array}{c}\text { Single } \\
\text { Black } \\
\text { Females } \\
\text { (std. dev.) }\end{array}$ \\
\hline Northeast region & 0.23 & 0.15 & 0.22 & 0.15 & 0.22 & 0.14 \\
\hline Midwest region & 0.29 & 0.18 & 0.29 & 0.22 & 0.28 & 0.23 \\
\hline South region & 0.30 & 0.60 & 0.28 & 0.54 & 0.28 & 0.53 \\
\hline West region & 0.18 & 0.07 & 0.22 & 0.09 & 0.21 & 0.10 \\
\hline SMSA & 0.48 & 0.64 & 0.55 & 0.73 & 0.57 & 0.71 \\
\hline Spouse: Annual hours worked & $\begin{array}{r}935.83 \\
(931.97)\end{array}$ & $\begin{array}{r}973.32 \\
(956.57)\end{array}$ & & & & \\
\hline Age & $\begin{array}{r}48.03 \\
(15.16)\end{array}$ & $\begin{array}{r}47.64 \\
(15.45)\end{array}$ & $\begin{array}{r}40.99 \\
(17.57)\end{array}$ & $\begin{array}{r}38.66 \\
(14.61)\end{array}$ & $\begin{array}{r}53.09 \\
(20.59)\end{array}$ & $\begin{array}{r}43.87 \\
(17.29)\end{array}$ \\
\hline Spouse: Age & $\begin{array}{r}45.41 \\
(14.69)\end{array}$ & $\begin{array}{r}44.53 \\
(14.57)\end{array}$ & & & & \\
\hline Number of kids in FU & $\begin{array}{r}0.92 \\
(1.13)\end{array}$ & $\begin{array}{r}1.21 \\
(1.34)\end{array}$ & $\begin{array}{r}0.11 \\
(0.46)\end{array}$ & $\begin{array}{r}0.18 \\
(0.58)\end{array}$ & $\begin{array}{r}0.37 \\
(0.82)\end{array}$ & $\begin{array}{r}1.04 \\
(1.28)\end{array}$ \\
\hline Whether kids in FU & 0.49 & 0.58 & 0.07 & 0.11 & 0.21 & 0.53 \\
\hline Number of dependents outside FU & $\begin{array}{r}0.25 \\
(0.77)\end{array}$ & $\begin{array}{r}0.29 \\
(0.93)\end{array}$ & $\begin{array}{r}0.35 \\
(0.80)\end{array}$ & $\begin{array}{r}0.56 \\
(1.02)\end{array}$ & $\begin{array}{r}0.15 \\
(0.62)\end{array}$ & $\begin{array}{r}0.10 \\
(0.42)\end{array}$ \\
\hline Whether dependents outside FU & 0.14 & 0.15 & 0.21 & 0.30 & 0.09 & 0.07 \\
\hline Health: fair or poor & 0.14 & 0.30 & 0.16 & 0.26 & 0.25 & 0.31 \\
\hline Spouse: Health: fair or poor & 0.12 & 0.28 & & & & \\
\hline Education: grade school & 0.08 & 0.18 & 0.07 & 0.12 & 0.13 & 0.15 \\
\hline Education: high school incomplete & 0.13 & 0.19 & 0.14 & 0.20 & 0.16 & 0.28 \\
\hline Education: high school diploma & 0.24 & 0.28 & 0.22 & 0.29 & 0.28 & 0.25 \\
\hline Education: high school diploma plus & 0.29 & 0.24 & 0.32 & 0.30 & 0.26 & 0.25 \\
\hline Education: college degree & 0.17 & 0.06 & 0.17 & 0.08 & 0.11 & 0.05 \\
\hline Education: advanced or professional degree & 0.10 & 0.05 & 0.08 & 0.01 & 0.06 & 0.02 \\
\hline Spouse: Education: grade school complete & 0.05 & 0.09 & & & & \\
\hline Spouse: Education: high school incomplete & 0.12 & 0.24 & & & & \\
\hline Spouse: Education: high school diploma & 0.36 & 0.27 & & & & \\
\hline Spouse: Education: high school diploma plus & 0.28 & 0.29 & & & & \\
\hline Spouse: Education: college degree & 0.13 & 0.05 & & & & \\
\hline Spouse: Education: advanced or professional degree & 0.06 & 0.05 & & & & \\
\hline Number of marriages & $\begin{array}{r}1.18 \\
(0.49)\end{array}$ & $\begin{array}{r}1.12 \\
(0.42)\end{array}$ & $\begin{array}{r}0.64 \\
(0.72)\end{array}$ & $\begin{array}{r}0.55 \\
(0.67)\end{array}$ & $\begin{array}{r}0.97 \\
(0.75)\end{array}$ & $\begin{array}{r}0.71 \\
(0.65)\end{array}$ \\
\hline Spouse: Number of marriages & $\begin{array}{r}1.18 \\
(0.47)\end{array}$ & $\begin{array}{r}1.12 \\
(0.45)\end{array}$ & & & & \\
\hline Tenure of current marriage & $\begin{array}{r}21.81 \\
(15.31)\end{array}$ & $\begin{array}{r}20.54 \\
(14.87)\end{array}$ & & & & \\
\hline Most recent marriage ended in widowhood & & & 0.10 & 0.10 & 0.36 & 0.21 \\
\hline Most recent marriage ended in divorce & & & 0.31 & 0.18 & 0.28 & 0.24 \\
\hline Number of children born or adopted & $\begin{array}{r}2.43 \\
(1.67)\end{array}$ & $\begin{array}{r}2.86 \\
(2.31)\end{array}$ & $\begin{array}{r}1.11 \\
(1.67)\end{array}$ & $\begin{array}{r}1.76 \\
(2.11)\end{array}$ & $\begin{array}{r}2.00 \\
(2.00)\end{array}$ & $\begin{array}{r}2.61 \\
(2.37)\end{array}$ \\
\hline Spouse: Number of children born or adopted & $\begin{array}{r}2.42 \\
(1.65)\end{array}$ & $\begin{array}{r}2.85 \\
(2.41)\end{array}$ & & & & \\
\hline Self-employed & 0.18 & 0.05 & 0.10 & 0.05 & 0.05 & 0.02 \\
\hline Spouse: Self-employed & 0.08 & 0.03 & & & & \\
\hline Number of siblings & $\begin{array}{r}2.30 \\
(2.65)\end{array}$ & $\begin{array}{r}3.73 \\
(3.96)\end{array}$ & $\begin{array}{r}2.32 \\
(2.71)\end{array}$ & $\begin{array}{r}3.63 \\
(3.99)\end{array}$ & $\begin{array}{r}2.56 \\
(2.91)\end{array}$ & $\begin{array}{r}3.78 \\
(4.02)\end{array}$ \\
\hline Spouse: Number of siblings & $\begin{array}{r}2.26 \\
(2.65)\end{array}$ & $\begin{array}{r}3.62 \\
(3.76)\end{array}$ & & & & \\
\hline Number of observations & 7700 & 2509 & 1415 & 1130 & 2744 & 3178 \\
\hline from 1984 wealth survey & 2561 & 910 & 442 & 335 & 898 & 1036 \\
\hline from 1989 wealth survey & 2777 & 931 & 502 & 426 & 912 & 1090 \\
\hline from 1994 wealth survey & 2362 & 668 & 471 & 369 & 934 & 1052 \\
\hline Number of couples/singles & 3444 & 1280 & 924 & 701 & 1562 & 1587 \\
\hline
\end{tabular}

Notes: Computed from the pooled sample using weights (see Table 1). "SMSA" refers to standard metropolitan statistical area, "FU" refers to family unit. 


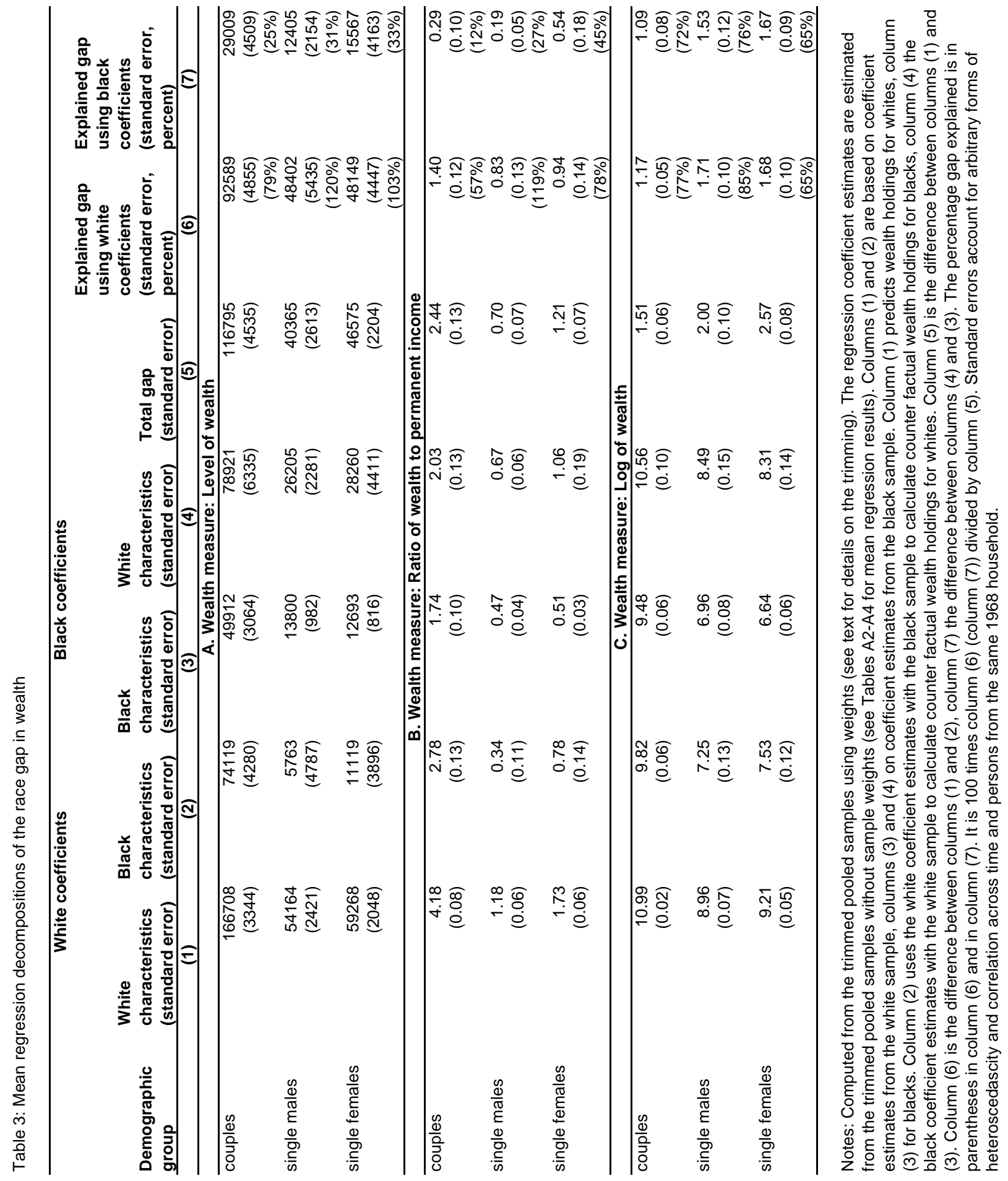




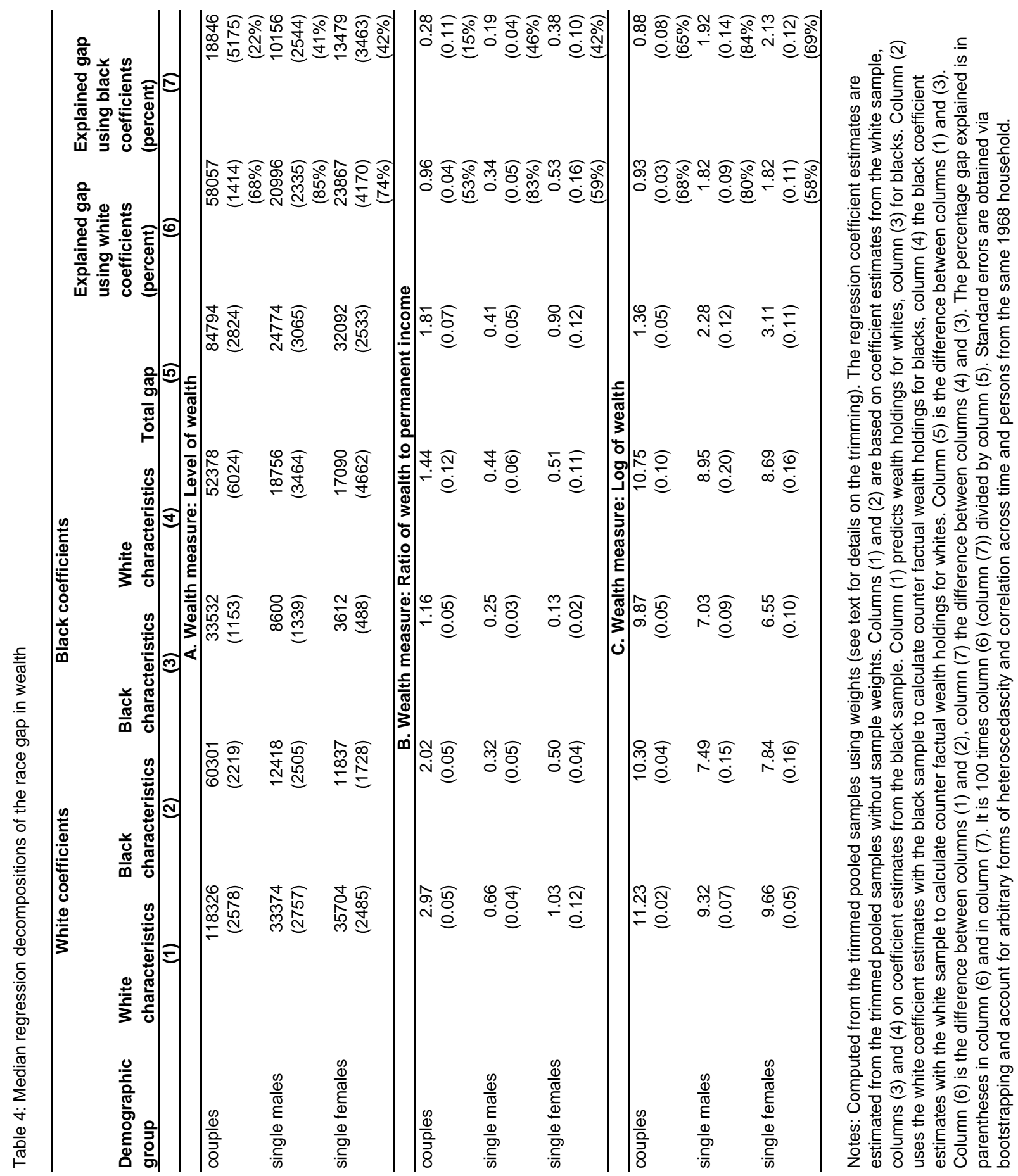




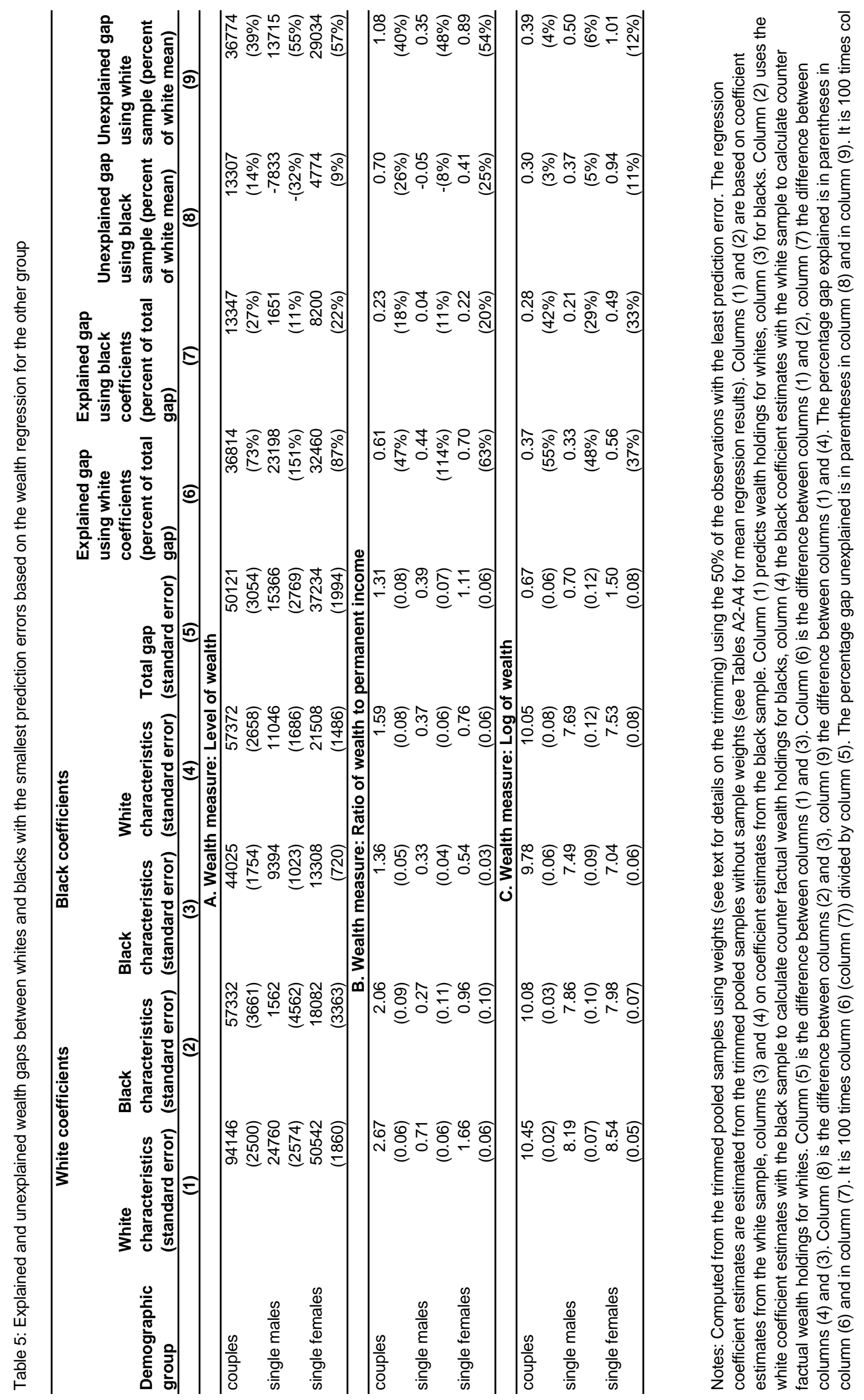




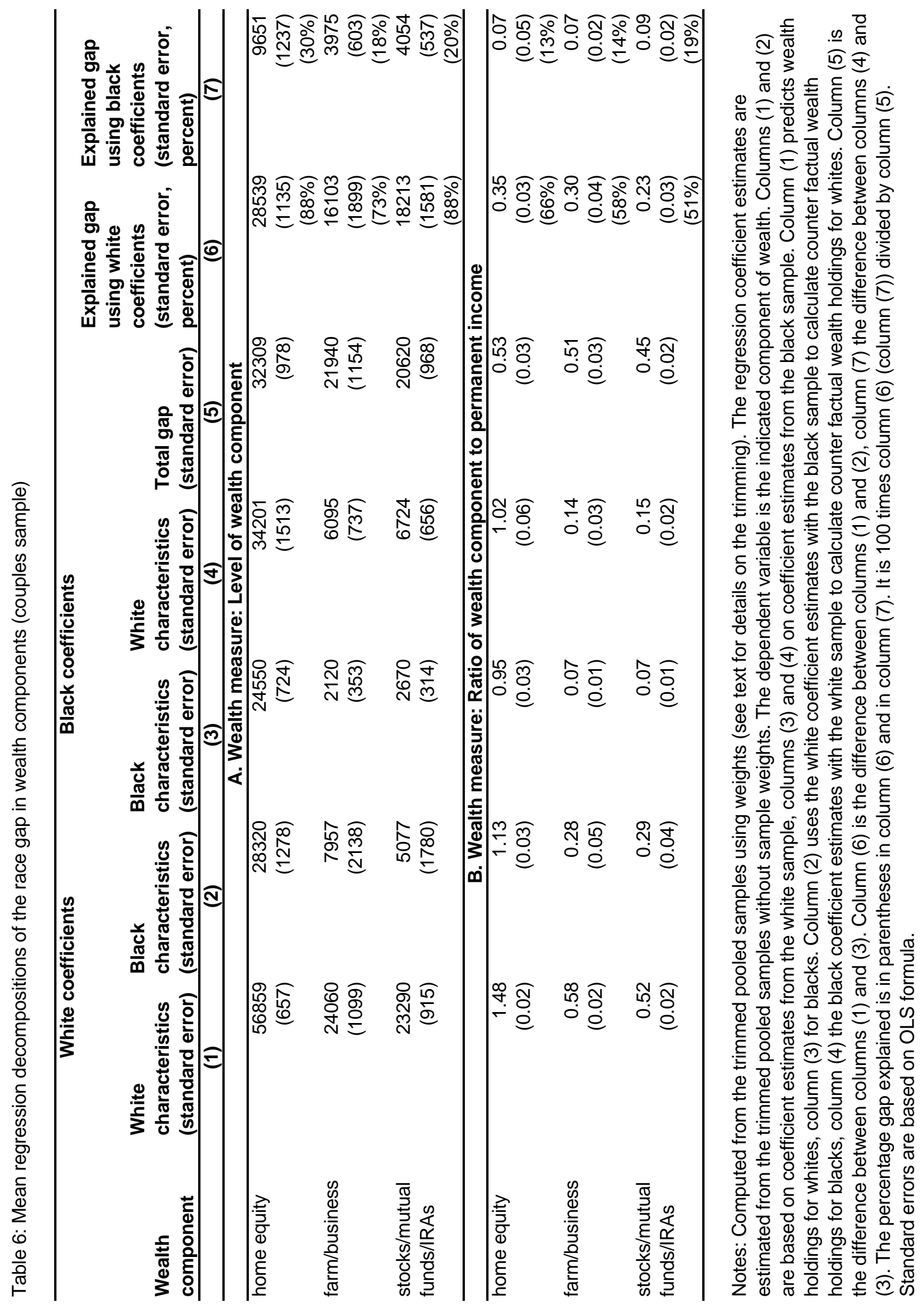


Table 7: Mean regression decompositions of the race gap in wealth (siblings sample)

\begin{tabular}{|c|c|c|c|c|c|c|c|}
\hline \multirow[t]{2}{*}{ Estimator } & $\begin{array}{l}\text { White } \\
\text { characteristics } \\
\text { (standard error) }\end{array}$ & $\begin{array}{l}\text { Black } \\
\text { characteristics } \\
\text { (standard error) }\end{array}$ & $\begin{array}{l}\text { Black } \\
\text { characteristics } \\
\text { (standard error) }\end{array}$ & $\begin{array}{l}\text { White } \\
\text { characteristics } \\
\text { (standard error) }\end{array}$ & $\begin{array}{l}\text { Total gap } \\
\text { (standard error) }\end{array}$ & $\begin{array}{l}\text { Explained gap } \\
\text { using white } \\
\text { coefficients } \\
\text { (standard error, } \\
\text { percent) }\end{array}$ & $\begin{array}{l}\text { Explained gap } \\
\text { using black } \\
\text { coefficients } \\
\text { (standard error, } \\
\text { percent) }\end{array}$ \\
\hline & (1) & (2) & (3) & (4) & (5) & (6) & (7) \\
\hline & \multicolumn{7}{|c|}{ A. Wealth measure: Level of wealth } \\
\hline$\overline{\mathrm{FE}}$ & $\begin{array}{l}64321 \\
(1160)\end{array}$ & $\begin{array}{l}15119 \\
(4697)\end{array}$ & $\begin{array}{r}17081 \\
(603)\end{array}$ & $\begin{array}{l}40258 \\
(2686)\end{array}$ & $\begin{array}{l}47240 \\
(1308)\end{array}$ & $\begin{array}{l}49202 \\
(5611) \\
(104 \%)\end{array}$ & $\begin{array}{l}23176 \\
(5639) \\
(49 \%)\end{array}$ \\
\hline FE on means & $\begin{array}{l}64281 \\
(1446)\end{array}$ & $\begin{array}{l}18591 \\
(7299)\end{array}$ & $\begin{array}{r}16963 \\
(677)\end{array}$ & $\begin{array}{l}27858 \\
(3546)\end{array}$ & $\begin{array}{l}47317 \\
(1596)\end{array}$ & $\begin{array}{l}45689 \\
(8806) \\
(97 \%)\end{array}$ & $\begin{array}{r}10895 \\
(4671) \\
(23 \%)\end{array}$ \\
\hline OLS & $\begin{array}{l}64321 \\
(1789)\end{array}$ & $\begin{array}{l}11666 \\
(3733)\end{array}$ & $\begin{array}{r}17081 \\
(794)\end{array}$ & $\begin{array}{l}42766 \\
(3774)\end{array}$ & $\begin{array}{l}47240 \\
(1957)\end{array}$ & $\begin{array}{r}52655 \\
(4031) \\
(111 \%)\end{array}$ & $\begin{array}{l}25685 \\
(3455) \\
(54 \%)\end{array}$ \\
\hline \multirow[t]{2}{*}{ OLS on means } & $\begin{array}{l}64463 \\
(1865)\end{array}$ & $\begin{array}{l}13350 \\
(4874)\end{array}$ & $\begin{array}{r}16898 \\
(781)\end{array}$ & $\begin{array}{l}34052 \\
(3435)\end{array}$ & $\begin{array}{l}47564 \\
(2022)\end{array}$ & $\begin{array}{r}51112 \\
(5041) \\
(107 \%) \\
\end{array}$ & $\begin{array}{r}17154 \\
(3251) \\
(36 \%) \\
\end{array}$ \\
\hline & \multicolumn{7}{|c|}{ B. Wealth measure: Ratio of wealth to permanent income } \\
\hline$\overline{F E}$ & $\begin{array}{r}1.30 \\
(0.02)\end{array}$ & $\begin{array}{r}0.55 \\
(0.09)\end{array}$ & $\begin{array}{r}0.49 \\
(0.02)\end{array}$ & $\begin{array}{r}0.73 \\
(0.07)\end{array}$ & $\begin{array}{r}0.82 \\
(0.03)\end{array}$ & $\begin{array}{r}0.75 \\
(0.11) \\
(92 \%)\end{array}$ & $\begin{array}{r}0.25 \\
(0.11) \\
(31 \%)\end{array}$ \\
\hline FE on means & $\begin{array}{r}1.30 \\
(0.03)\end{array}$ & $\begin{array}{r}0.58 \\
(0.15)\end{array}$ & $\begin{array}{r}0.48 \\
(0.02)\end{array}$ & $\begin{array}{r}0.56 \\
(0.10)\end{array}$ & $\begin{array}{r}0.82 \\
(0.03)\end{array}$ & $\begin{array}{r}0.72 \\
(0.19) \\
(88 \%)\end{array}$ & $\begin{array}{r}0.08 \\
(0.12) \\
(10 \%)\end{array}$ \\
\hline OLS & $\begin{array}{r}1.30 \\
(0.04)\end{array}$ & $\begin{array}{r}0.46 \\
(0.08)\end{array}$ & $\begin{array}{r}0.49 \\
(0.02)\end{array}$ & $\begin{array}{r}0.86 \\
(0.07)\end{array}$ & $\begin{array}{r}0.82 \\
(0.04)\end{array}$ & $\begin{array}{r}0.85 \\
(0.08) \\
(104 \%)\end{array}$ & $\begin{array}{r}0.37 \\
(0.07) \\
(45 \%)\end{array}$ \\
\hline \multirow[t]{2}{*}{ OLS on means } & $\begin{array}{r}1.30 \\
(0.04)\end{array}$ & $\begin{array}{r}0.47 \\
(0.10)\end{array}$ & $\begin{array}{r}0.48 \\
(0.02)\end{array}$ & $\begin{array}{r}0.72 \\
(0.07)\end{array}$ & $\begin{array}{r}0.82 \\
(0.04)\end{array}$ & $\begin{array}{r}0.82 \\
(0.10) \\
(101 \%)\end{array}$ & $\begin{array}{r}0.24 \\
(0.07) \\
(30 \%) \\
\end{array}$ \\
\hline & \multicolumn{7}{|c|}{ C. Wealth measure: Log of wealth } \\
\hline$\overline{\mathrm{FE}}$ & $\begin{array}{r}9.49 \\
(0.03)\end{array}$ & $\begin{array}{r}7.60 \\
(0.10)\end{array}$ & $\begin{array}{r}7.13 \\
(0.03)\end{array}$ & $\begin{array}{r}8.86 \\
(0.12)\end{array}$ & $\begin{array}{r}2.37 \\
(0.04)\end{array}$ & $\begin{array}{r}1.90 \\
(0.13) \\
(80 \%)\end{array}$ & $\begin{array}{r}1.73 \\
(0.16) \\
(73 \%)\end{array}$ \\
\hline FE on means & $\begin{array}{r}9.45 \\
(0.03)\end{array}$ & $\begin{array}{r}7.70 \\
(0.17)\end{array}$ & $\begin{array}{r}7.12 \\
(0.04)\end{array}$ & $\begin{array}{r}8.88 \\
(0.15)\end{array}$ & $\begin{array}{r}2.33 \\
(0.05)\end{array}$ & $\begin{array}{r}1.75 \\
(0.24) \\
(75 \%)\end{array}$ & $\begin{array}{r}1.76 \\
(0.21) \\
(75 \%)\end{array}$ \\
\hline OLS & $\begin{array}{r}9.49 \\
(0.04)\end{array}$ & $\begin{array}{r}7.45 \\
(0.10)\end{array}$ & $\begin{array}{r}7.13 \\
(0.05)\end{array}$ & $\begin{array}{r}9.07 \\
(0.09)\end{array}$ & $\begin{array}{r}2.37 \\
(0.06)\end{array}$ & $\begin{array}{r}2.04 \\
(0.08) \\
(86 \%)\end{array}$ & $\begin{array}{r}1.95 \\
(0.08) \\
(82 \%)\end{array}$ \\
\hline OLS on means & $\begin{array}{r}9.46 \\
(0.04)\end{array}$ & $\begin{array}{r}7.42 \\
(0.10)\end{array}$ & $\begin{array}{r}7.11 \\
(0.05)\end{array}$ & $\begin{array}{r}9.07 \\
(0.10)\end{array}$ & $\begin{array}{r}2.34 \\
(0.06)\end{array}$ & $\begin{array}{r}2.03 \\
(0.09) \\
(87 \%)\end{array}$ & $\begin{array}{r}1.95 \\
(0.09) \\
(83 \%)\end{array}$ \\
\hline
\end{tabular}

Notes: Computed from the trimmed pooled siblings samples without sample weights (see text for details on the trimming). The regression coefficient estimates are estimated from the trimmed pooled siblings samples without sample weights. "OLS" denotes an OLS estimate, "FE" an OLS-fixed effects estimate, and "FE on means" a OLS-fixed effects estimate based on the mean of all observations for a given individual. Columns (1) and (2) are based on coefficient estimates from the white sample, columns (3) and (4) on coefficient estimates from the black sample. Column (1) predicts wealth holdings for whites, column (3) for blacks. Column (2) uses the white coefficient estimates with the black sample to calculate counter factual wealth holdings for blacks, column (4) the black coefficient estimates with the white sample to calculate counter factual wealth holdings for whites. Column (5) is the difference between columns (1) and (3). Column (6) is the difference between columns (1) and (2), column (7) the difference between columns (4) and (3). The percentage gap explained is in parentheses in column (6) and in column (7). It is 100 times column (6) (column (7)) divided by column (5). Standi 
Table 8: Descriptive statistics for growth in wealth variables (5 year changes, couples sample)

\begin{tabular}{|c|c|c|c|c|}
\hline & \multicolumn{2}{|c|}{ Full Sample } & \multicolumn{2}{|c|}{ Trimmed Sample } \\
\hline & $\begin{array}{l}\text { White } \\
\text { Couples } \\
\text { (std. dev.) }\end{array}$ & $\begin{array}{l}\text { Black } \\
\text { Couples } \\
\text { (std. dev.) }\end{array}$ & $\begin{array}{l}\text { White } \\
\text { Couples } \\
\text { (std. dev.) }\end{array}$ & $\begin{array}{l}\text { Black } \\
\text { Couples } \\
\text { (std. dev.) }\end{array}$ \\
\hline \multirow[t]{2}{*}{$\Delta$ Log of wealth including main home equity (In) } & 0.34 & 0.30 & 0.39 & 0.15 \\
\hline & $(1.72)$ & $(2.25)$ & $(1.62)$ & $(2.05)$ \\
\hline \multirow[t]{2}{*}{$\Delta$ Wealth including main home equity } & 33560 & 255 & 36160 & 8237 \\
\hline & $(530443)$ & $(316361)$ & $(178330)$ & $(60593)$ \\
\hline \multirow[t]{2}{*}{$\Delta$ Ratio of wealth including main home equity to permanent income (rt) } & 1.24 & 0.18 & 1.28 & 0.45 \\
\hline & $(10.61)$ & $(10.87)$ & $(3.71)$ & $(2.11)$ \\
\hline \multirow[t]{2}{*}{$\Delta$ Value home (incl. 0 ) } & 8577 & 3676 & 8953 & 3723 \\
\hline & $(59644)$ & $(30790)$ & $(57784)$ & (30785) \\
\hline \multirow[t]{2}{*}{$\Delta$ Value farm/business (incl. 0) } & 6722 & 211 & 3645 & 281 \\
\hline & $(282714)$ & $(17480)$ & $(115905)$ & (17359) \\
\hline \multirow[t]{2}{*}{$\Delta$ Value stock/mf/ira (incl. 0) } & 15909 & 1077 & 12048 & 1079 \\
\hline & $(130397)$ & $(16398)$ & (74094) & (16412) \\
\hline \multirow[t]{2}{*}{$\Delta$ Ratio of value home (incl. 0 ) to permanent income $(\mathrm{rt})$} & 0.38 & 0.25 & 0.39 & 0.25 \\
\hline & (1.39) & $(1.21)$ & $(1.33)$ & $(1.21)$ \\
\hline \multirow[t]{2}{*}{$\Delta$ Ratio of value farm/business (incl. 0 ) to permanent income $(\mathrm{rt}$ ) } & 0.19 & 0.01 & 0.10 & 0.02 \\
\hline & $(5.14)$ & $(0.65)$ & $(2.18)$ & $(0.65)$ \\
\hline \multirow[t]{2}{*}{$\Delta$ Ratio of value stock/mf/ira (incl. 0 ) to permanent income (rt) } & 0.35 & 0.03 & 0.32 & 0.03 \\
\hline & $(1.88)$ & $(0.41)$ & $(1.64)$ & $(0.41)$ \\
\hline Number of observations & 4227 & 1216 & 4174 & 1214 \\
\hline Wealth growth from 1984 to 1989 & 2099 & 644 & 2073 & 643 \\
\hline Wealth growth from 1989 to 1994 & 2128 & 572 & 2101 & 571 \\
\hline Number of couples/singles & 2594 & 789 & 2574 & 788 \\
\hline
\end{tabular}

Notes: Computed without sample weights. The right two columns refer to the full sample, the left two columns to the trimmed sample (see text for details on the trimming). "Value of stock/mf/ira" refers to the value of shares of stock in publicly held corporations, mutual funds or investment funds, including stocks in IRAs. (In) indicates that the corresponding descriptive statistics are computed from the log-trimmed sample and (rt) refers to the ratio-trimmed sample. The remaining descriptive statistics are computed from the level-trimmed sample. 


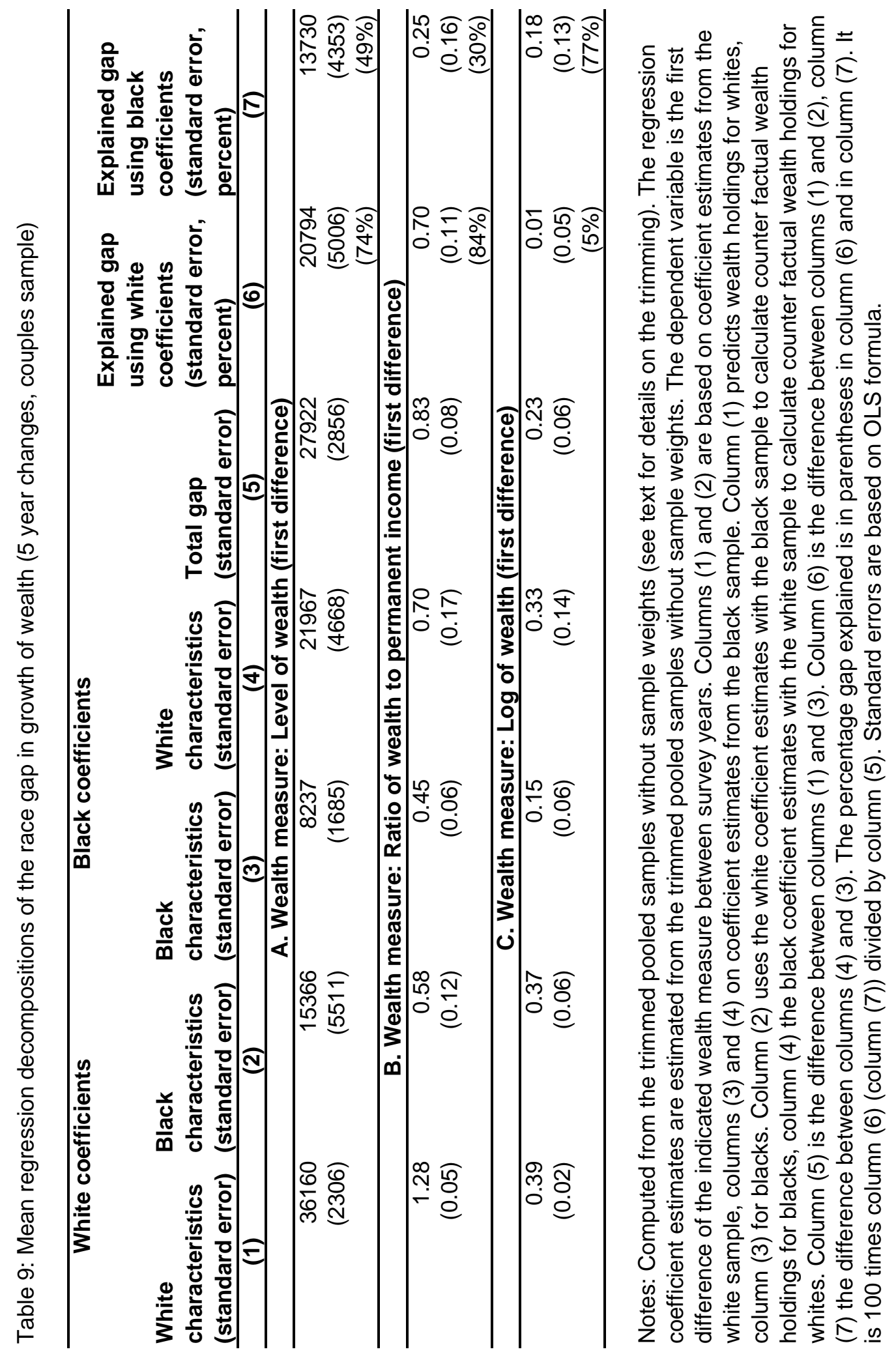


Table A1: Descriptive statistics for wealth and income variables

\begin{tabular}{|c|c|c|c|c|c|c|}
\hline & $\begin{array}{l}\text { White } \\
\text { Couples } \\
\text { (std. dev.) }\end{array}$ & $\begin{array}{l}\text { Black } \\
\text { Couples } \\
\text { (std. dev.) }\end{array}$ & $\begin{array}{c}\text { Single White } \\
\text { Males } \\
\text { (std. dev.) }\end{array}$ & $\begin{array}{c}\text { Single Black } \\
\text { Males } \\
\text { (std. dev.) }\end{array}$ & $\begin{array}{l}\text { Single White } \\
\text { Females } \\
\text { (std. dev.) }\end{array}$ & $\begin{array}{l}\text { Single } \\
\text { Black } \\
\text { Females } \\
\text { (std. dev.) }\end{array}$ \\
\hline \multirow[t]{2}{*}{ Log of wealth including main home equity (In) } & 11.00 & 9.50 & 8.99 & 7.20 & 9.23 & 6.86 \\
\hline & $(2.03)$ & $(2.33)$ & $(2.74)$ & $(2.80)$ & $(2.77)$ & $(2.87)$ \\
\hline \multirow[t]{2}{*}{ Wealth including main home equity } & 167589 & 52361 & 54077 & 14698 & 59725 & 14869 \\
\hline & $(298571)$ & $(98897)$ & $(112398)$ & $(27992)$ & $(91477)$ & (37399) \\
\hline \multirow[t]{2}{*}{ Ratio of wealth including main home equity to permanent income (rt) } & 4.20 & 1.76 & 1.17 & 0.55 & 1.73 & 0.60 \\
\hline & $(5.82)$ & $(2.93)$ & $(2.10)$ & $(1.15)$ & $(2.77)$ & $(1.32)$ \\
\hline \multirow[t]{2}{*}{ Value home } & 68384 & 38128 & 48613 & 29576 & 51698 & 30645 \\
\hline & (73963) & $(60740)$ & $(57001)$ & $(22080)$ & $(45934)$ & (33991) \\
\hline \multirow[t]{2}{*}{ Value farm/business } & 123644 & 52590 & 61273 & 15752 & 61728 & 25758 \\
\hline & $(306434)$ & (62635) & (98002) & $(21364)$ & $(73830)$ & (31834) \\
\hline \multirow[t]{2}{*}{ Value stock/mf/ira } & 58380 & 26837 & 25783 & 8623 & 31700 & 8852 \\
\hline & $(175934)$ & $(51006)$ & $(61674)$ & $(11312)$ & $(62237)$ & (14959) \\
\hline \multirow[t]{2}{*}{ Value home (incl. 0) } & 56979 & 25293 & 17403 & 6473 & 24778 & 9082 \\
\hline & $(72167)$ & $(52650)$ & $(41307)$ & $(16008)$ & $(40967)$ & (23200) \\
\hline \multirow[t]{2}{*}{ Value farm/business (incl. 0) } & 24435 & 2347 & 6742 & 324 & 3205 & 104 \\
\hline & $(144850)$ & $(17116)$ & $(37743)$ & (3791) & $(21695)$ & (2595) \\
\hline \multirow[t]{2}{*}{ Value stock/mf/ira (incl. 0) } & 23136 & 4073 & 6448 & 581 & 7326 & 516 \\
\hline & $(114377)$ & $(22081)$ & $(32801)$ & (3647) & (32768) & (4165) \\
\hline \multirow[t]{2}{*}{ Ratio of value home to permanent income (rt) } & 1.77 & 1.38 & 1.10 & 1.13 & 1.51 & 1.36 \\
\hline & $(1.78)$ & $(1.63)$ & $(1.30)$ & $(0.89)$ & $(1.41)$ & $(1.37)$ \\
\hline \multirow[t]{2}{*}{ Ratio of value farm/business to permanent income (rt) } & 2.94 & 1.51 & 1.21 & 0.57 & 1.90 & 1.19 \\
\hline & $(4.72)$ & $(1.63)$ & $(1.80)$ & $(0.88)$ & $(2.52)$ & $(1.78)$ \\
\hline \multirow[t]{2}{*}{ Ratio of value stock/mf/ira to permanent income (rt) } & 1.29 & 0.69 & 0.52 & 0.28 & 0.94 & 0.32 \\
\hline & $(2.87)$ & $(1.23)$ & $(1.09)$ & $(0.39)$ & $(1.90)$ & $(0.62)$ \\
\hline \multirow[t]{2}{*}{ Ratio of value home (incl. 0) to permanent income (rt) } & 1.48 & 0.92 & 0.40 & 0.25 & 0.73 & 0.40 \\
\hline & $(1.76)$ & $(1.48)$ & $(0.94)$ & $(0.63)$ & $(1.24)$ & $(0.97)$ \\
\hline \multirow[t]{2}{*}{ Ratio of value farm/business (incl. 0) to permanent income (rt) } & 0.59 & 0.07 & 0.13 & 0.01 & 0.10 & 0.00 \\
\hline & $(2.42)$ & $(0.46)$ & $(0.71)$ & $(0.15)$ & $(0.71)$ & $(0.14)$ \\
\hline \multirow[t]{2}{*}{ Ratio of value stock/mf/ira (incl. 0) to permanent income (rt) } & 0.51 & 0.10 & 0.13 & 0.02 & 0.22 & 0.02 \\
\hline & $(1.92)$ & $(0.54)$ & $(0.59)$ & $(0.12)$ & $(1.00)$ & $(0.17)$ \\
\hline Whether home & 0.83 & 0.66 & 0.36 & 0.22 & 0.48 & 0.30 \\
\hline Whether farm/business & 0.20 & 0.04 & 0.11 & 0.02 & 0.05 & 0.00 \\
\hline Whether stock/mf/ira & 0.40 & 0.15 & 0.25 & 0.07 & 0.23 & 0.06 \\
\hline \multirow[t]{2}{*}{ Log of taxable non-asset income (In) } & 10.33 & 10.06 & 9.67 & 9.12 & 9.26 & 8.91 \\
\hline & $(0.78)$ & $(0.78)$ & $(0.89)$ & (1.07) & $(0.87)$ & $(0.90)$ \\
\hline \multirow[t]{2}{*}{ Permanent log-income (In) } & 10.35 & 10.07 & 9.68 & 9.13 & 9.27 & 8.92 \\
\hline & $(0.79)$ & $(0.78)$ & $(0.90)$ & (1.07) & $(0.88)$ & $(0.90)$ \\
\hline \multirow[t]{2}{*}{ Total taxable non-asset income } & 10.72 & 10.33 & 10.55 & 9.92 & 10.52 & 9.94 \\
\hline & $(0.49)$ & $(0.53)$ & $(0.57)$ & $(0.72)$ & $(0.56)$ & $(0.63)$ \\
\hline \multirow[t]{2}{*}{ Permanent income } & 45978 & 32449 & 44981 & 28417 & 38934 & 25041 \\
\hline & (17339) & $(12747)$ & (16722) & (9685) & $(13712)$ & (7872) \\
\hline \multirow[t]{2}{*}{ Spouse: Permanent log-income (In) } & 10.66 & 10.25 & & & & \\
\hline & $(0.49)$ & $(0.56)$ & & & & \\
\hline Spouse: Permanent income & 42181 & 30085 & & & & \\
\hline & $(19923)$ & $(13681)$ & & & & \\
\hline Number of observations & 7599 & 2507 & 1390 & 1128 & 2693 & 3168 \\
\hline from 1984 wealth survey & 2536 & 908 & 435 & 335 & 889 & 1036 \\
\hline from 1989 wealth survey & 2739 & 931 & 494 & 424 & 895 & 1088 \\
\hline from 1994 wealth survey & 2324 & 668 & 461 & 369 & 909 & 1044 \\
\hline Number of couples/singles & 3423 & 1279 & 712 & 700 & 1547 & 1585 \\
\hline
\end{tabular}

Notes: Computed from the trimmed pooled sample using weights (see text for details on the trimming). The weights are normalized so that for each subgroup the means are estimates of the average of the population means for 1984, 1989, and 1994. "Value of stock/mf/ira" refers to the value of shares of stock in publicly held corporations, mutual funds or investment funds, including stocks in IRAs. The definition of permanent income is given in the text. (In) indicates that the corresponding descriptive statistics are computed from the log-trimmed sample and (rt) refers to the ratio-trimmed sample. The remaining descriptive statistics are computed from the level-trimmed sample. 
Table A2: Mean regression results for couples

\begin{tabular}{|c|c|c|c|c|c|c|}
\hline & \multicolumn{3}{|c|}{ White } & \multicolumn{3}{|c|}{ Black } \\
\hline & Log & Ratio & Level & Log & Ratio & Level \\
\hline Intercept & $-21.7989^{* *}$ & -0.0675 & -39117.0000 & -22.8839 & $-1.3982^{* *}$ & $-70752.0000^{* *}$ \\
\hline Log-income & $-1.5952 *$ & & & 2.2444 & & \\
\hline Permanent log-income & 8.1983 ** & & & -2.9890 & & \\
\hline Spouse: Permanent log-income & -2.2695 & & & 4.5059 & & \\
\hline Log-income squared & $0.1488 * *$ & & & $0.2870 * *$ & & \\
\hline Permanent log-income squared & -0.3092 & & & $0.5743 *$ & & \\
\hline Spouse: Permanent log-income squared & 0.1531 & & & -0.2361 & & \\
\hline Log-income * Permanent log-income & -0.0705 & & & -0.7634 * & & \\
\hline Spouse: Log-income * Permanent log-income & -0.0386 & & & 0.0587 & & \\
\hline Income & & $1.9141 \mathrm{E}-05^{* *}$ & -0.2146 & & 3.3877E-05 ** & -0.3451 \\
\hline Permanent income & & $-5.2800 \mathrm{E}-07$ & $-3.4312^{\star *}$ & & $-1.4743 \mathrm{E}-05$ & -0.6723 \\
\hline Spouse: Permanent income & & $-1.4054 \mathrm{E}-05$ & $4.0627^{* *}$ & & 2.1436E-05 & 3.5190 ** \\
\hline Income squared & & $2.4188 \mathrm{E}-11$ & $1.3000 \mathrm{E}-07$ & & $-1.2084 \mathrm{E}-13$ & $-3.1610 \mathrm{E}-06$ \\
\hline Permanent income squared & & $4.4732 \mathrm{E}-10$ ** & $5.8835 \mathrm{E}-05^{* *}$ & & $3.8751 \mathrm{E}-10$ & $-1.4957 \mathrm{E}-05$ \\
\hline Spouse: Permanent income squared & & $-2.0611 \mathrm{E}-10$ & $-4.2375 \mathrm{E}-05^{* *}$ & & $-3.5930 \mathrm{E}-10$ & $-2.1588 \mathrm{E}-05$ \\
\hline Income * Permanent income & & $-4.3337 \mathrm{E}-10$ * & $-1.4719 \mathrm{E}-05$ & & $-2.4194 \mathrm{E}-10$ & $5.0980 \mathrm{E}-05$ * \\
\hline Spouse: Income * Permanent income & & $2.9342 \mathrm{E}-10$ & $3.6135 \mathrm{E}-05^{* *}$ & & $-1.6451 \mathrm{E}-10$ & $-2.2277 \mathrm{E}-05$ \\
\hline Midwest region & 0.0168 & -0.2232 & -7421.6442 & $0.4127^{*}$ & 0.0480 & 1265.7768 \\
\hline South region & 0.0415 & -0.0486 & 5958.6141 & $0.6262 * *$ & $0.4115^{* *}$ & 14127.0000 ** \\
\hline West region & $0.2057^{* *}$ & $0.4485^{* *}$ & 21529.0000 ** & 0.2318 & $0.7943^{* *}$ & 31739.0000 ** \\
\hline SMSA & $-0.3412 * *$ & $-0.2146 *$ & -7450.8221 & $-0.5637^{* *}$ & -0.1498 & -3552.9321 \\
\hline Spouse: Annual hours worked & $-1.7600 \mathrm{E}-04$ ** & $-4.5300 \mathrm{E}-04$ ** & $-22.8612^{\star *}$ & $-5.4500 \mathrm{E}-06$ & $-5.5239 E-05$ & -3.5653 \\
\hline Age (centered) & $0.0293^{* *}$ & $0.0751^{* *}$ & $4329.6431^{* *}$ & $0.0511^{* *}$ & $0.0751^{* *}$ & 2505.5531 ** \\
\hline Age (centered) squared & $-2.2350 \mathrm{E}-03$ ** & $2.6010 \mathrm{E}-03^{* *}$ & 59.1751 & $-2.5310 \mathrm{E}-03^{* *}$ & $-3.4800 \mathrm{E}-04$ & 9.7264 \\
\hline Age (centered) cubed & $7.8702 \mathrm{E}-05^{* *}$ & $-2.2510 \mathrm{E}-06$ & -4.2798 & $-1.6220 \mathrm{E}-06$ & $-8.7545 \mathrm{E}-05^{* *}$ & -1.9949 \\
\hline Age (centered) quadrubled & $-7.9800 \mathrm{E}-07^{*}$ & $-1.3930 \mathrm{E}-06$ & 0.0281 & 1.1220E-06 & $2.0930 \mathrm{E}-06$ & 0.0320 \\
\hline Spouse: Age (centered) & $3.6378 \mathrm{E}-02$ ** & $9.8807 \mathrm{E}-02$ ** & 4415.1455 ** & 7.7090E-03 & $-2.8880 \mathrm{E}-03$ & 68.8697 \\
\hline Spouse: Age (centered) squared & $-1.0290 \mathrm{E}-03^{* *}$ & 2.1370E-03 & 62.3552 & $1.7490 \mathrm{E}-03^{* *}$ & $1.7510 \mathrm{E}-03^{* *}$ & 2.8262 \\
\hline Spouse: Age (centered) cubed & 1.4964E-05 & $-1.2300 \mathrm{E}-04$ ** & $-6.0100 * *$ & $-5.4391 \mathrm{E}-05$ & $-5.9480 \mathrm{E}-06$ & -1.0846 \\
\hline Spouse: Age (centered) quadrubled & $-3.3400 \mathrm{E}-07$ & $6.4200 \mathrm{E}-07$ & 0.0733 & $-3.2300 \mathrm{E}-07$ & $-9.2400 \mathrm{E}-07$ & 0.0187 \\
\hline Number of kids in FU & $-0.1109^{* *}$ & 0.0430 & 6404.6329 ** & -0.0941 & 0.0231 & 3495.9925 ** \\
\hline Whether kids in FU & -0.0288 & -0.0949 & -3285.6762 & 0.1559 & -0.1238 & -6504.4755 \\
\hline Number of dependents outside FU & $0.0551 * *$ & 0.1610 & 8326.6910 & 0.0514 & 0.1186 & 3225.5923 \\
\hline Whether dependents outside FU & $-0.2465^{* *}$ & 0.0531 & -3135.5860 & 0.0639 & 0.0657 & 4731.0842 \\
\hline Health: fair or poor & -0.1263 & -0.3114 & -15378.0000 ** & 0.0359 & 0.1484 & 730.6555 \\
\hline Spouse: Health: fair or poor & $-0.3242^{* *}$ & -0.4258 * & -24049.0000 ** & -0.0655 & -0.1407 & -3201.9317 \\
\hline Education: high school incomplete & -0.0294 & 0.6623 * & 21246.0000 * & 0.2173 & $0.5084^{* *}$ & 18484.0000 ** \\
\hline Education: high school diploma & 0.0522 & $0.9862 * *$ & $34824.0000 * *$ & 0.2868 & 0.3676 * & 11206.0000 ** \\
\hline Education: high school diploma plus & 0.1255 & $1.3554 * *$ & 44350.0000 ** & $0.4932 * *$ & $0.4919^{* *}$ & 13435.0000 ** \\
\hline Education: college degree & 0.1055 & $1.4484^{* *}$ & 43645.0000 ** & 0.3732 & 0.4017 & 7257.9354 \\
\hline Education: advanced or professional degree & -0.0290 & $0.8928^{* *}$ & 33654.0000 * & 0.3877 & 0.6230 & 26954.0000 \\
\hline Spouse: Education: high school incomplete & 0.2264 & $0.9971^{* *}$ & 24332.0000 * & 0.3752 & $0.4291^{* *}$ & 8188.5868 * \\
\hline Spouse: Education: high school diploma & 0.2908 * & $1.0442 * *$ & 25319.0000 * & 0.5753 ** & $0.8198 * *$ & 21104.0000 ** \\
\hline Spouse: Education: high school diploma plus & 0.2894 * & 1.3260 ** & 36712.0000 ** & 0.5440 ** & $0.7712^{* *}$ & 17212.0000 ** \\
\hline Spouse: Education: college degree & 0.2955 & $1.3906^{* *}$ & 31609.0000 * & $0.6244 * *$ & $0.8816^{* *}$ & 19266.0000 ** \\
\hline Spouse: Education: advanced or professional degree & $0.4282 * *$ & $2.0305^{* *}$ & 61795.0000 ** & 0.5189 & 2.1256 ** & 65983.0000 ** \\
\hline Self-employed & 1.1108 ** & $3.6853^{* *}$ & 150010.0000 ** & $0.9857^{* *}$ & $1.4398^{* \star}$ & 57415.0000 ** \\
\hline Spouse: Self-employed & $0.3819^{* *}$ & $1.4847^{* *}$ & 47916.0000 ** & 0.2394 & -0.1853 & -3784.2222 \\
\hline Number of siblings & -0.0094 & 0.0095 & -647.5563 & 0.0097 & 0.0073 & 151.6589 \\
\hline Spouse: Number of siblings & -0.0219 ** & $-0.0593 * \star$ & $-1992.5843 *$ & -0.0095 & -0.0091 & $-657.1305 *$ \\
\hline Number of marriages & -0.0032 & 0.0141 & 346.1726 & 0.1684 & -0.0579 & -1621.5048 \\
\hline Tenure of current marriage & $0.0106^{* *}$ & 0.0220 * & 871.3506 * & $0.0415^{* *}$ & $0.0252^{* *}$ & $571.1674^{* *}$ \\
\hline Spouse: Number of marriages & $-0.1304 *$ & -0.1868 & -8937.3251 & 0.0879 & -0.0732 & 576.2912 \\
\hline Number of children born or adopted & -0.0059 & -0.1086 & -7581.7513 ** & -0.0109 & -0.0264 & -381.4341 \\
\hline Spouse: Number of children born or adopted & -0.0519 & -0.0015 & 2304.9317 & 0.0333 & 0.0485 & -531.7740 \\
\hline Time dummy 1984 & $0.1533^{* *}$ & $-0.5203^{* *}$ & -6554.1813 & 0.0228 & -0.0971 & 2089.8504 \\
\hline Time dummy 1994 & $-0.2170^{* *}$ & 0.2877 & $-17045.0000 * *$ & -0.0708 & 0.1233 & -6356.0637 \\
\hline Wealth effect of a unit increase in income & & & 0.6388 & & & 0.6875 \\
\hline Wealth effect of a unit increase in permanent income & & & 1.0436 & & & -0.0173 \\
\hline Spouse: Wealth effect of a unit increase in permanent income & & & 1.9790 & & & 0.9135 \\
\hline Wealth effect of a unit inrease in all of the above & & & 3.6614 & & & 1.5838 \\
\hline Number of observations & 7627 & 7600 & 7599 & 2479 & 2506 & 2507 \\
\hline Adjusted R-squared & 0.4585 & 0.348 & 0.5395 & 0.3671 & 0.2558 & 0.2677 \\
\hline
\end{tabular}

Notes: Computed from the trimmed pooled samples (see text for details on the trimming). ${ }^{* \star}\left({ }^{\star}\right)$ indicates that the coefficient is different from zero at a $5 \%(10 \%)$ significance level. Standard errors account for arbitrary forms of heteroscedascity and correlation across time and persons from the same 1968 household. The omitted categories are northwest for region, grade school for education, and the time dummy for the 1989 wealth survey. 
Table A3: Mean regression results for single males

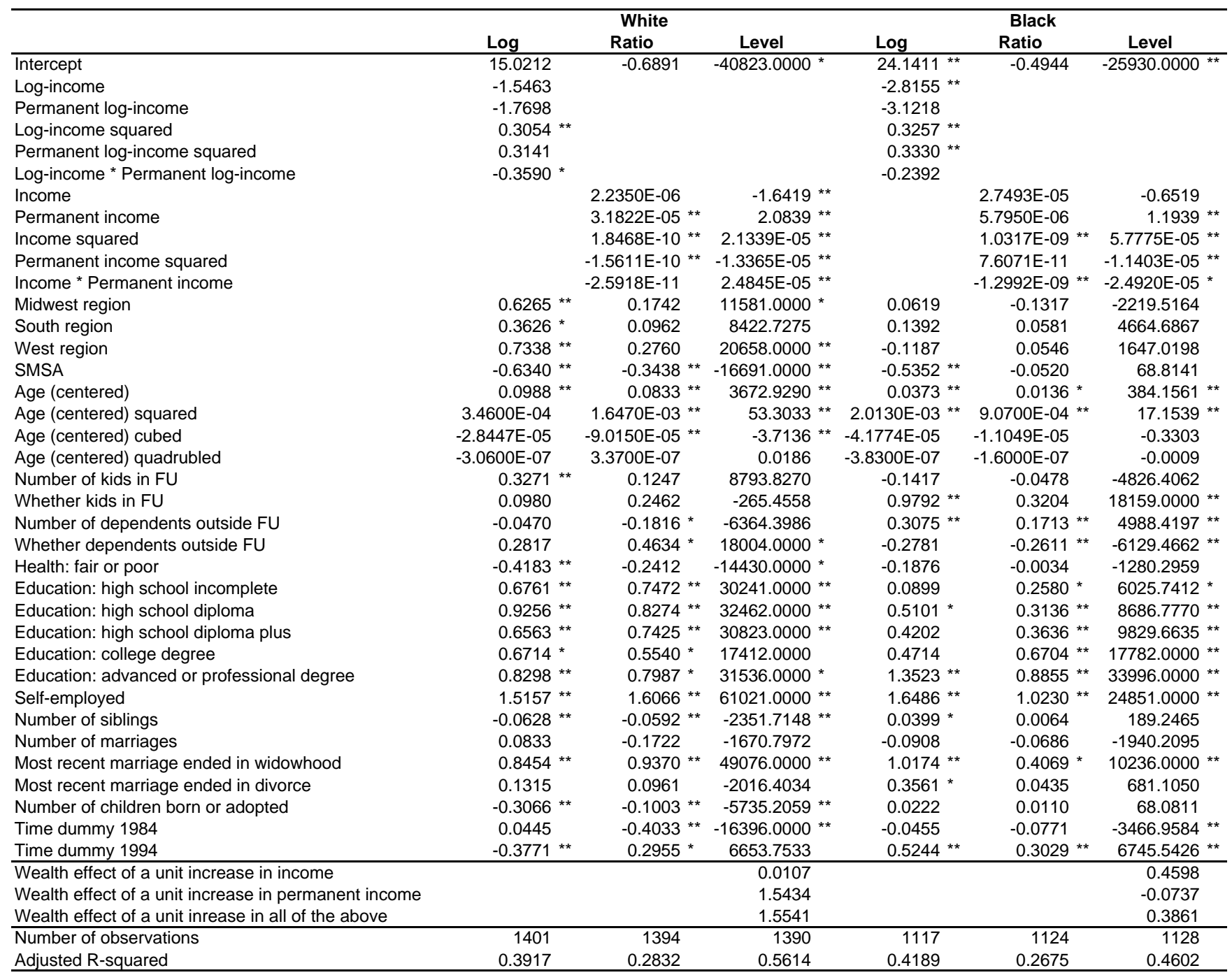

Notes: See Table A2. 
Table A4: Mean regression results for single females

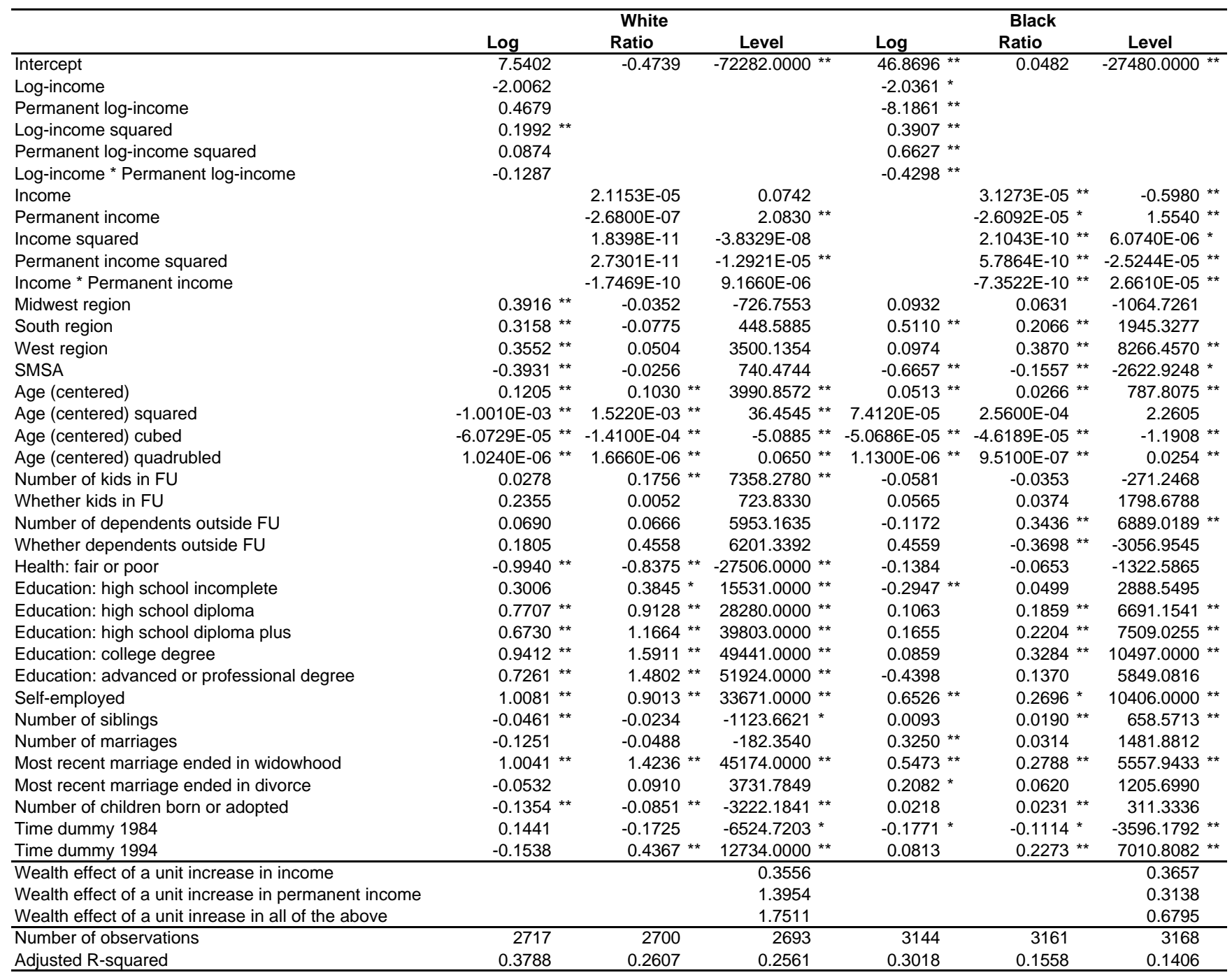

Notes: See Table A2. 